\title{
Financial Factors: Implications for Output Gaps
}




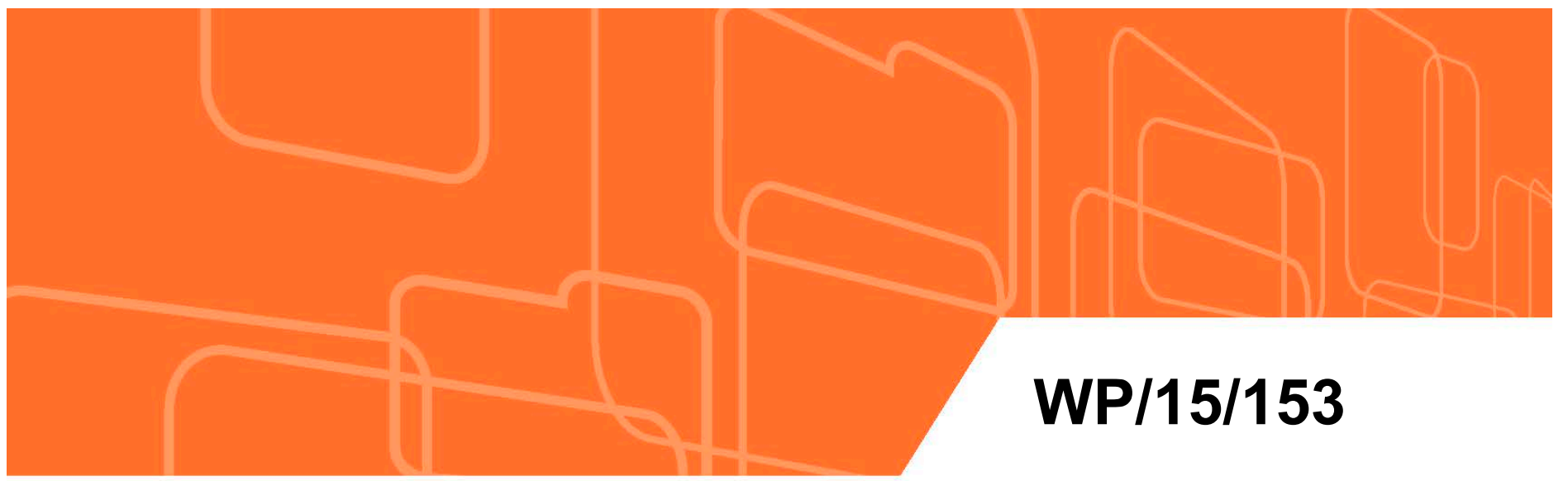

\title{
IMF Working Paper
}

\section{Financial Factors: Implications for Output Gaps}

\author{
by Pau Rabanal and Marzie Taheri Sanjani
}

IMF Working Papers describe research in progress by the author(s) and are published to elicit comments and to encourage debate. The views expressed in IMF Working Papers are those of the author(s) and do not necessarily represent the views of the IMF, its Executive Board, or IMF management.
I
N T E R N A T I O N A L
$M O N E$ T A R Y
$F \cup N D$ 


\title{
IMF Working Paper
}

European Department and Research Department

\author{
Financial Factors: Implications for Output Gaps \\ Prepared by Pau Rabanal and Marzie Taheri Sanjani ${ }^{1}$
}

Authorized for distribution by Helge Berger and Giovanni dell'Ariccia

July 2015

\section{IMF Working Papers describe research in progress by the author(s) and are published to elicit comments and to encourage debate. The views expressed in IMF Working Papers are those of the author(s) and do not necessarily represent the views of the IMF, its Executive Board, or IMF management.}

\begin{abstract}
We suggest a new approach for analyzing the role of financial variables and shocks in computing the output gap. We estimate a two-region DSGE model for the euro area, with financial frictions at the household level, between 2000-2013. After joining the monetary union, a decline in some countries' borrowing costs contributed to a credit, housing and real boom and bust cycle. We show that financial frictions amplified economic fluctuations and the measure of the output gap in those countries. On the contrary, in countries such as France and Germany, financial frictions played a minor role in output gap measures. We also present evidence of the trade-offs faced by the European Central Bank when trying to stabilize two regions in a currency union with unsynchronized economic cycles.
\end{abstract}

Keywords: Monetary Union, Output Gap, Financial Frictions, and Bayesian Estimation. JEL Codes: C51, E32, E52.

Author's E-Mail Address: prabanal@imf.org; mtaherisanjani@,imf.org

\footnotetext{
${ }^{1}$ The authors would like to thank Tamim Bayoumi, Helge Berger, Olivier Blanchard, Giovanni Dell'Ariccia, Giang Ho, Ivanna Vladkova Hollar, Olivier Jeanne, Peter Karadi, Nir Klein, Luc Laeven, Albert Marcet, Reza Moghadam, Ernesto Ramirez Rigo, Jorge Roldós, Antonio Spilimbergo, Lars Svensson and Jerome Vandenbussche for useful comments and discussions.
} 


\section{Contents}

$\begin{array}{ll}\text { I. INTRODUCTION } & \underline{\mathbf{5}}\end{array}$

II. The Model $\quad \underline{\mathbf{9}}$

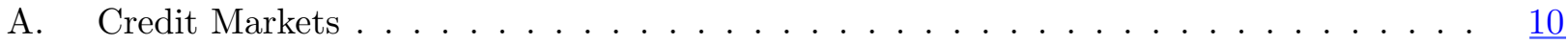

A.1. Domestic Intermediaries . . . . . . . . . . . . . . . 10

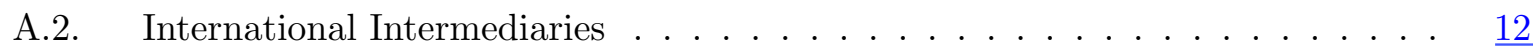

B. Households . . . . . . . . . . . . . . . . . . . . . . . 12

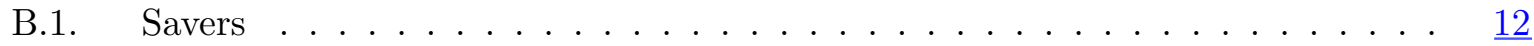

B.2. Labor Unions and Wage Setting . . . . . . . . . . . . . . 14

B.3. Borrowers ..................... 14

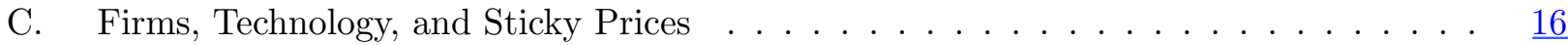

C.1. Final Goods Producers . . . . . . . . . . . . . . . . . . 16

C.2. Intermediate Goods Producers . . . . . . . . . . . . . . . . . . 17

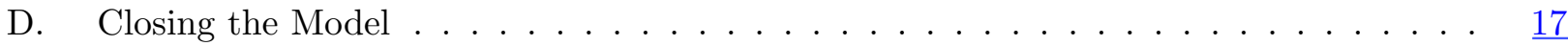

D.1. Market Clearing Conditions . . . . . . . . . . . . . . 17

D.2. Monetary Policy and Interest Rates . . . . . . . . . . . . . . . . . . 18

III.Parameter Estimates $\quad \underline{\mathbf{1 9}}$

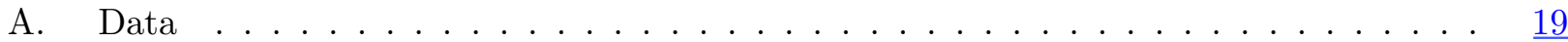

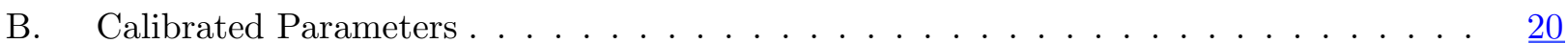

C. Prior and Posterior Distributions . . . . . . . . . . . . . . . 22

D. Variance Decomposition: The Role of Demand and Financial Shocks . . . . . . . . . $\underline{26}$

IV.Decomposing the Business Cycle in the Euro Area

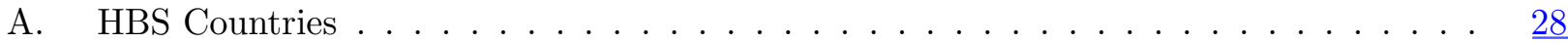

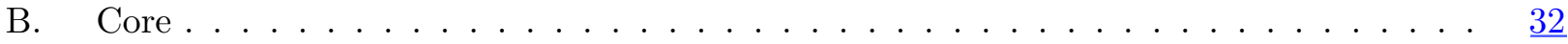

C. The Role of Financial Frictions . . . . . . . . . . . . . . . . 32

V. Does One Monetary Policy Fit All?

$\begin{array}{ll}\text { VI.IMPUlSE RESPONSE AnAlysis } & \underline{\mathbf{3 7}}\end{array}$

$\begin{array}{ll}\text { VIICONCLUSIONS } & \underline{41}\end{array}$

A Appendix: Data And Sources $\quad \underline{46}$

B Appendix: Linearized Conditions $\quad \underline{47}$

\section{List of Tables}

$1 \quad$ Calibrated Parameters . . . . . . . . . . . . . . . . . 21

2 Prior and Posterior Distributions, Economic Parameters . . . . . . . . . 24

3 Prior and Posterior Distributions, AR(1) Shock Processes . . . . . . . . . . $2 \underline{25}$

4 Variance Decomposition . . . . . . . . . . . . . . . 27 


\section{List of Figures}

1 Ten Year Government Bond Rates in Selected Euro Area Countries . . . . . . . . $\underline{6}$

2 Excess Credit and Unemployment Rates . . . . . . . . . . . . . . . . 7

3 Shock Decomposition, Output and Output Gaps . . . . . . . . . . . . . $\underline{30}$

4 Shock Decomposition, Credit and House Prices . . . . . . . . . . . . . . $\underline{31}$

5 Output Gaps and Financial Wedges . . . . . . . . . . . . . . . . $\underline{33}$

6 Natural Rates of Interest and Deviations from Taylor Rule . . . . . . . . . . . $\underline{36}$

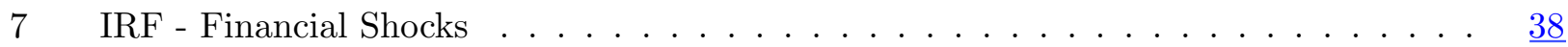

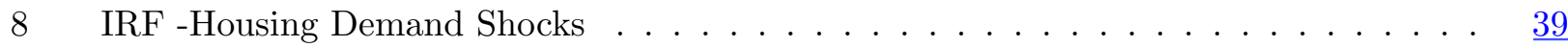

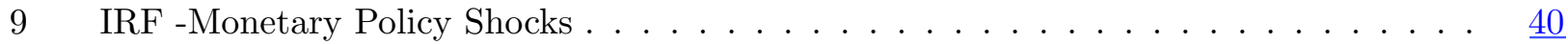




\section{Introduction}

The concept of the output gap, the difference between actual and potential GDP, is key in macroeconomic policy formulation. Central banks need an assessment of the output gap to understand if future inflationary pressures are building up. In addition, the central bank may also have an explicit objective of stabilizing the output gap. The task of estimating output gaps is complicated by the fact that we do not observe potential output. Therefore, assumptions are needed to construct a measure of potential output, and an ex-post assessment of the accuracy of the estimates is not possible. A simple and popular way to obtain a measure of potential output and the output gap is the Hodrick and Prescott (1997, HP) filter, which fits a smooth trend to a time series. In the HP filter, potential output is a weighted average of past and future values of actual output. Since this is the only information that is required, the HP filter cannot explain what is driving potential output and the output gap. Therefore, the use of multivariate filters provides the next step to incorporate additional information. As an example, Benes et al. (2010) present a multivariate filter that makes use of additional variables (such as inflation and unemployment) and economic relationships (such as a Phillips Curve and Okun's Law) to estimate potential output. However, the recent Global Financial Crisis (GFC) has shown that large fluctuations in asset markets (including housing and credit), if left unaddressed, can lead to large boom and bust real GDP cycles, with important welfare consequences. Before the GFC, these imbalances did not necessarily show up as inflationary pressures in the consumer price index (CPI), which suggested that the surge in asset prices (in particular, housing), credit and GDP could be sustainable. The severe credit and housing busts that followed in many industrialized countries after 2007 suggest actual GDP growth significantly outpaced potential during the boom years.

One such example is the case of some countries of the Economic and Monetary Union (EMU), that witnessed a strong reduction in borrowing costs during the first years of the euro, and a sharp increase in the aftermath of the GFC. Greece, Ireland, Italy, Portugal, and Spain's borrowing costs (measured as the 10-year rate on government bonds) displayed a similar behavior between 1995 and 2014, at least qualitatively (Figure 1). Before the creation of the euro, these countries faced higher borrowing costs than France and Germany, but these interest rate differentials disappeared after these countries joined the currency union. Lower rates during that period contributed to a surge in residential investment, credit and house prices inflation in some of these countries (in particular in Greece, Ireland and Spain), but not widespread CPI inflation. Contrary to France and Germany, these countries faced higher borrowing costs after the GFC, and in particular during the 2010-2011 period, thereby worsening the recession.

In this paper, we study the role of financial factors, including the decline in risk premia and accelerator effects, in explaning macroeconomic fluctuations and the assessment of the output gap in the euro area. We conduct the study for two main regions of the euro area. Throughout the paper, we refer to the aggregate of France and Germany as the "core" of the euro area, and to the aggregate of the remaining countries in Figure 1 as the "euro area countries with high borrowing spreads" or HBS countries. While there are similarities in this second group, such as the behavior of borrowing costs, it is important to stress that there are also differences. 
Ireland's borrowing costs were not as high as the other countries before the creation of the euro, yet it went through a housing and credit boom and bust cycle as much as Spain did. Portugal had a credit boom, but growth was never as high as Greece, Ireland and Spain during the 2000s. Italy's credit growth and real house price appreciation was milder, and real GDP growth was lower during the early 2000s than the rest of the HBS countries. ${ }^{1}$

Figure 1: Ten Year Government Bond Rates in Selected Euro Area Countries

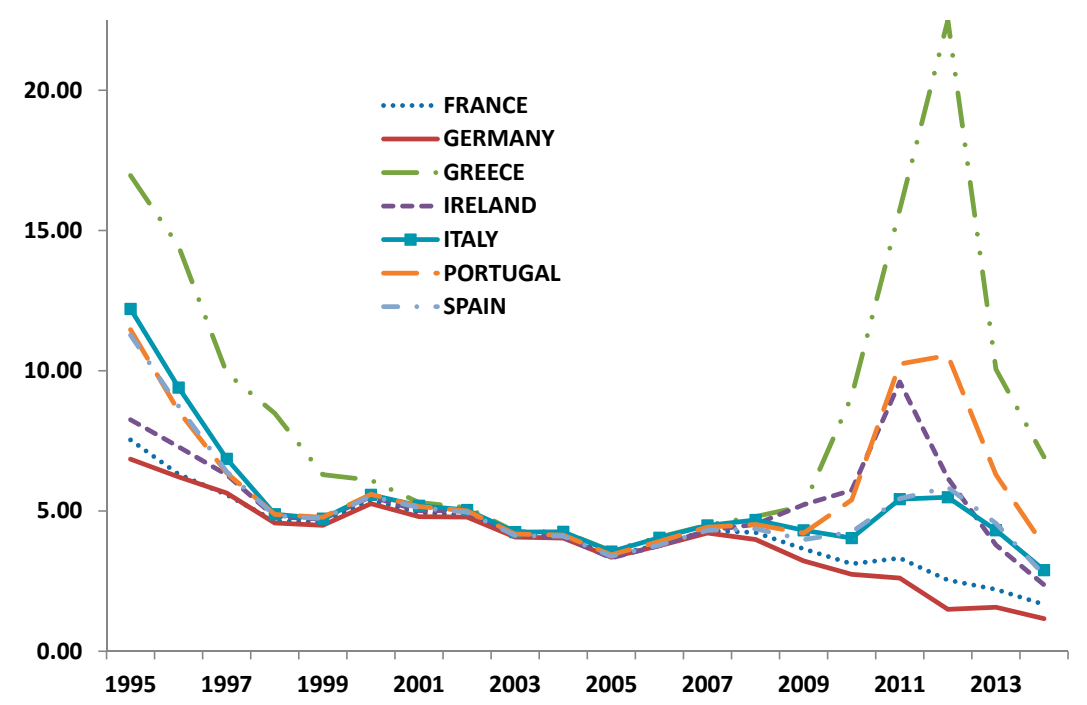

Note: Horizontal axis shows the year, and the vertical axis presents interest rates in percent.

The outcome of the GFC, and more generally the literature that documents the comovement between credit, house prices and real activity, provides a clear case for expanding the information set to measure potential output and the output gap using financial data. ${ }^{2}$ In addition, in recent years, inflation appears to have been less responsive to changes in economic slack, thereby reducing its informational content to estimate the output gap, a phenomenon known as the "flattening" of the Phillips Curve. ${ }^{3}$ However, there appears to be a consistent negative correlation between countries experiencing a credit boom and the unemployment rate, which can be empirically used. Figure 2 shows the bivariate relationship between excess credit and unemployment in the two regions of the euro area using quarterly data between 2006Q1 and 2013Q4. ${ }^{4}$ As Figure 2 shows, there is a strong negative relationship between excess credit and

\footnotetext{
${ }^{1}$ Ideally, we would want to use a multi-country model of the EMU for each country member, but this would be computationally burdensome. Therefore, we group countries according to the behavior of borrowing costs as shown in Figure 1.

${ }^{2}$ See Claessens, Kose and Terrones (2009), and Christiano, Ilut, Motto and Rostagno (2008).

${ }^{3}$ See IMF (2013).

${ }^{4}$ The unemployment rate is a weighted average using the European Central Bank (ECB) weights to compute the Harmonized Index of Consumer Prices (HICP). Excess credit is the deviation between seasonally adjusted loans to nonfinancial corporations and its 4-year moving average.
} 
the unemployment rate only in the euro area HBS countries, but this relationship was absent in the core. This different response to the fluctuations in credit will turn out to be key in our output gap measures later in the paper. ${ }^{5}$ Using a model with financial frictions and housing, this paper tries to identify the drivers of the output gap more accurately, including the role of interest rate spreads fluctuations in a currency union.

Figure 2: Excess Credit and Unemployment Rates
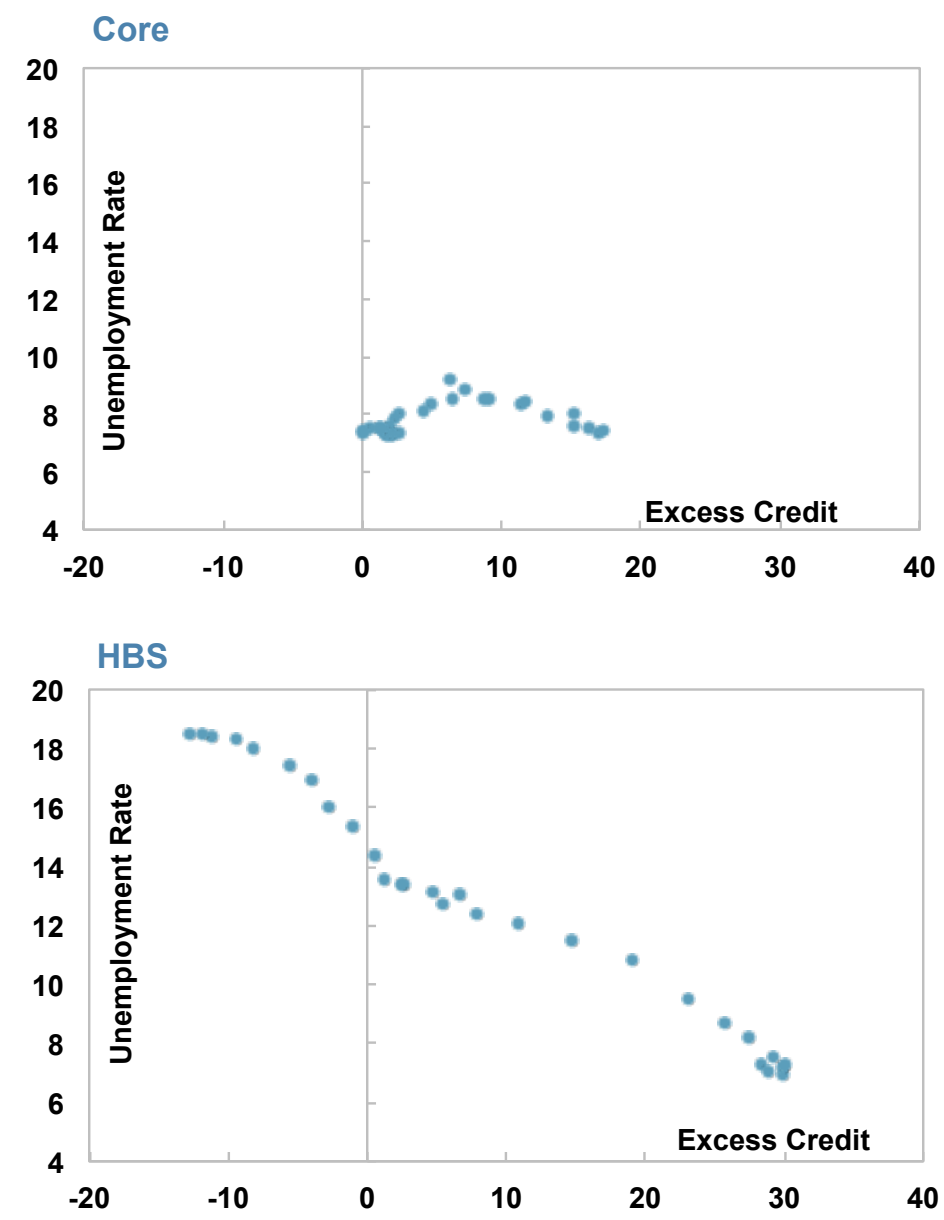

Note: Horizontal axis shows excess credit in percentage deviation from trend and vertical axis presents unemployment rates in percent.

Several alternative methods have been proposed to deal with the measurement of potential output with financial variables. One method consists in incorporating financial variables in a multivariate filter environment (see Borio et al. 2014, Berger et al., 2015). In this approach, the coefficients are reduced-form and have little guidance from theory. Therefore, it does not allow for an understanding of the channels through which financial variables affect the real economy. Hence, a more structural approach specifies and estimates a Dynamic Stochastic

\footnotetext{
${ }^{5}$ See also the speech by Stein (2014) on the importance of financial volatility in explaining the unemployment cycle in the United States.
} 
General Equilibrium (DSGE) model with financial frictions. Christiano, Motto, and Rostagno (2014) estimate the financial accelerator model of Bernanke, Gertler and Gilchrist (1999) and show the importance of financial frictions and financial shocks in explaining macroeconomic fluctuations. Furlanetto, Gelain and Taheri Sanjani (2014) use a similar framework to derive a measure of potential output, understood as the counterfactual level of output when nominal rigidities (sticky prices and wages) and inefficient shocks (price and wage mark-up shocks) are removed from the model. They confirm the important amplification role of financial frictions, the key role of financial shocks to explain fluctuations, and what is more important, that the implications for the behavior of the output gap of the United States are radically different once the financial sector is introduced. ${ }^{6}$

In this paper, we follow the DSGE modeling approach to estimate the output gap in the euro area, using a two-region model of a currency union that incorporates housing and financial frictions with balance sheet effects at the household level (see Quint and Rabanal, 2014). ${ }^{7}$ Once the model is estimated with thirteen macroeconomic time series and Bayesian methods, we perform a variance decomposition exercise to understand the sources of the boom-and-bust cycle in the euro area during the last fifteen years. Risk premium shocks (both at the region level and in the housing market) and housing demand shocks were the main source of the boom and bust cycle in some of the HBS countries of the euro area. Moreover, the introduction of financial frictions matters: the model gives a larger cycle when these features are taken into account, and the aggregate output gap measure for the HBS group appears more consistent with the narrative evidence. For instance, the HP filter gives a negative output gap during the mid-2000s and a close-to-zero output gap by end-2013. On the contrary, the DSGE model implies that the output gap was positive in the HBS countries for most of the 2000s, and about -4 percent by end-2013. ${ }^{8}$ According to our estimates, the cycle was less volatile in the core and was driven by non-financial factors: technology and aggregate demand shocks. The measure of output gap consistent with the model is very similar to the one constructed by the HP filter for the core of the euro area, because of the absence of a credit boom. We also show the trade-offs that the European Central Bank (ECB) faced when trying to conduct a single monetary policy with two regions facing different business cycles.

The rest of the paper is organized as follows. Section 2 presents the model, while Section 3 presents the econometric methodology and parameter estimates. Section 4 discusses the model-consistent measures of potential output and the output gap and the drivers in each region. Section 5 presents impulse response functions to selected shocks in the model, while Section 6 studies the monetary policy trade-offs faced by the ECB. Section 7 concludes.

\footnotetext{
${ }^{6}$ Galí, Smets and Wouters (2012) show that the measure of output gap also depends on introducing labor market rigidities and unemployment as an observable variable in a DSGE model.

${ }^{7}$ The model has several nominal and real frictions to fit the data, and a closed-form expression for the output gap cannot be derived. See Cúrdia and Woodford (2009) for a model with financial frictions at the household level, where a term involving credit frictions affects the Phillips curve and output gap expressions.

${ }^{8}$ In a companion paper, Berger et al. (2015) compare output gaps using multivariate filters similar to Borio et al. (2014) and a DSGE model like the one presented in this paper.
} 


\section{The Model}

The model is an extension of Quint and Rabanal (2014), with sticky wages and price markup shocks. We use a two-region model of a common currency area where savings and investment can differ, and where a region can obtain credit financing from the other. ${ }^{9}$ We ignore developments coming from outside the euro area and do not include a rest-of-the-world block. There is no evidence suggesting that external (outside of the EMU) shocks triggered the housing and credit boom and bust cycle in some countries of the euro area, and adding another region would complicate the analysis and the estimation.

The theoretical framework consists of a two-region, two-sector, two-agent general equilibrium model of a single currency area. The two regions are of size $n$ and $1-n$. There are two types of goods, durables and non-durables, that are produced under monopolistic competition and nominal rigidities. While non-durables are traded across countries, durable goods are non-tradable. In each region, there are two types of agents, savers (size $\lambda$ in each region) and borrowers $(1-\lambda)$, who differ in their discount factor and habit formation parameter. Both agents consume non-durable goods and purchase durable goods to increase their housing stock. Borrowers are more impatient than savers and have a preference for early consumption, which creates the condition for credit to occur in equilibrium. In addition, borrowers are hit by an idiosyncratic quality or valuation shock to their housing stock, which affects the value of collateral that they can use to borrow against. ${ }^{10}$ Hence, we adapt the mechanism of Bernanke, Gertler and Gilchrist (1999), henceforth BGG, to the household side and to residential investment: shocks to the valuation of housing affect the balance sheet of borrowers, which in turn affect the default rate on mortgages and the lending-deposit spread.

There are two types of financial intermediaries. Domestic financial intermediaries take deposits from savers, grant loans to borrowers, and issue bonds. International financial intermediaries trade these bonds across countries to channel funds from one region to the other. In compensation for this service, international financial intermediaries charge a risk premium which depends on the net foreign asset position of the region. Therefore, savings and (residential) investment need not to be balanced at the region level period by period, since excess credit demand in one region can be met by funding coming from elsewhere in the monetary union.

In what follows, we only present the home region block of the model, by describing the domestic and international credit markets, households, and firms. Monetary policy is conducted by a central bank that targets the union-wide CPI inflation rate, and also reacts to fluctuations in the union-wide real GDP growth. The rest of the euro area region block is characterized by a similar structure regarding credit markets, households and firms. Unless specified, all shocks follow zero-mean AR(1) processes in logs.

\footnotetext{
${ }^{9}$ This is an advantage over models where the euro area is treated as a single country, such as the Smets and Wouters (2003) model, that cannot explain intra-union imbalances.

${ }^{10}$ We could also assume that savers are hit by a housing quality shock. Since they do not borrow and use their housing stock as collateral, this quality shock would not have any macroeconomic impact.
}

CInternational Monetary Fund. Not for Redistribution 


\section{A. Credit Markets}

We adapt the BGG financial accelerator idea to the housing market, by introducing default risk in the mortgage market, and a lending-deposit spread that depends on housing market conditions. There are two main differences with respect to the BGG mechanism. First, there are no agency problems or asymmetric information in the model, and borrowers will only default if they find themselves underwater: that is, when the value of their outstanding debt is higher than the value of the house they own. Second, unlike the BGG setup, we assume that the one-period lending rate is pre-determined and does not depend on the state of the economy, which seems to be a more realistic assumption. ${ }^{11}$

\section{A.1. Domestic Intermediaries}

Domestic financial intermediaries collect deposits from savers $S_{t}$, for which they pay a deposit rate $R_{t}$, and extend loans to borrowers $S_{t}^{B}$ for which they charge the lending rate $R_{t}^{L}$. Credit granted to borrowers is backed by the value of the housing stock that they own $\left(P_{t}^{D} D_{t}^{B}\right)$, where $P_{t}^{D}$ is the nominal house price and $D_{t}^{B}$ is the housing stock owned by borrowers. We introduce risk in the credit and housing markets by assuming that each borrower (indexed by $j$ ) is subject to an idiosyncratic quality shock to the value of her housing stock, $\omega_{t}^{j}$, that is $\log$-normally distributed with $\mathrm{CDF} F(\omega)$. We choose the mean and standard deviation so that $E \omega_{t}=1$ and, hence, there is idiosyncratic risk but not aggregate risk in the housing market. This assumption implies that $\log \left(\omega_{t}^{j}\right) \sim N\left(-\frac{\sigma_{\omega, t}^{2}}{2}, \sigma_{\omega, t}^{2}\right)$, with $\sigma_{\omega, t}$ being the standard deviation characterizing the quality shock. This standard deviation is time-varying, and follows an AR(1) process in logs:

$$
\log \left(\sigma_{\omega, t}\right)=\left(1-\rho_{\sigma_{\omega}}\right) \log \left(\bar{\sigma}_{\omega}\right)+\rho_{\sigma_{\omega}} \log \left(\sigma_{\omega, t-1}\right)+u_{\omega, t}
$$

with $u_{\omega, t} \sim N\left(0, \sigma_{u_{\omega}}\right)$

The quality shock $\omega_{t}^{j}$ can lead to mortgage defaults and affects the spread between lending and deposit rates. The realization of the shock is known at the end of the period. High realizations of $\omega_{t-1}^{j}$ allow households to repay their loans in full, and hence they repay the full amount of their outstanding loan $R_{t-1}^{L} S_{t-1}^{B}$. Realizations of $\omega_{t-1}^{j}$ that are low enough make households default on their loans in period $t$. After the household defaults on her loan, the bank calls a debt-collection agency that forces the household to repay the value of the housing stock after the shock has realized, $\omega_{t-1}^{j} P_{t}^{D} D_{t}^{B}$. After paying this amount, the household keeps her house. These debt-collection agencies charge banks a fraction $\mu$ of the value of the house. The profits of these agencies are transferred to savers, who own them. The value of the idiosyncratic shock is common knowledge, so households will only default when they are underwater. ${ }^{12}$

When granting credit, financial intermediaries do not know the cut-off value of those house-

\footnotetext{
${ }^{11} \mathrm{~A}$ similar approach is taken by Suh (2012) and Zhang (2009).

${ }^{12}$ Under this assumption, no fraction of the housing stock is destroyed during the foreclosure process. If, as in BGG, a fraction of the collateral was lost during foreclosure, risk shocks might have unrealistic expansionary effects on housing and residential investment. See Forlati and Lambertini (2010).
} 
holds that default and those who do not. The ex-ante threshold value expected by banks is thus given by:

$$
\bar{\omega}_{t}^{a} E_{t}\left[P_{t+1}^{D} D_{t+1}^{B}\right]=R_{t}^{L} S_{t}^{B}
$$

Intermediaries behave in a risk-neutral way and require the expected return from granting one euro of credit to be equal to the funding rate of banks, which equals the deposit rate $\left(R_{t}\right)$ :

$$
\begin{aligned}
R_{t} & =E_{t}\left\{(1-\mu) \int_{0}^{\bar{\omega}_{t}^{a}} \omega d F\left(\omega, \sigma_{\omega, t}\right) \frac{P_{t+1}^{D} D_{t+1}^{B}}{S_{t}^{B}}+\left[1-F\left(\bar{\omega}_{t}^{a}, \sigma_{\omega, t}\right)\right] R_{t}^{L}\right\} \\
& =E_{t}\left\{(1-\mu) G\left(\bar{\omega}_{t}^{a}, \sigma_{\omega, t}\right) \frac{P_{t+1}^{D} D_{t+1}^{B}}{S_{t}^{B}}+\left[1-F\left(\bar{\omega}_{t}^{a}, \sigma_{\omega, t}\right)\right] R_{t}^{L}\right\},
\end{aligned}
$$

with $\left[1-F\left(\bar{\omega}_{t}^{a}, \sigma_{\omega, t}\right)\right]=\int_{\bar{\omega}_{t}^{a}}^{\infty} d F\left(\omega ; \sigma_{\omega, t}\right) d \omega$ being the expected probability that the shock exceeds the ex-ante threshold $\bar{\omega}_{t}^{a}$ and $G\left(\bar{\omega}_{t}^{a}, \sigma_{\omega, t}\right)=\int_{0}^{\bar{\omega}_{t}^{a}} \omega d F\left(\omega ; \sigma_{\omega, t}\right)$ being the expected value of the shock conditional on the shock being less than $\bar{\omega}_{t}^{a}$. The participation constraint (2) ensures that the opportunity costs $R_{t}$ are equal to the expected returns, which are given by the expected foreclosure settlement as percent of outstanding credit (the first term of the right hand side of equation 2) and the expected repayment of households with higher housing values (the second term). Due to the fees paid to debt-collection agencies to make defaulting households pay their debts, financial intermediaries only receive a fraction $(1-\mu)$ of the mortgage settlement.

The aggregate balance sheet of domestic financial intermediaries in the home region is:

$$
n \lambda\left(S_{t}-B_{t}\right)=n(1-\lambda) S_{t}^{B}
$$

where $B_{t}$ are claims on financial intermediaries in the rest of the euro area region (as explained below). Combined with the participation constraint equation (2), we obtain the following relationship:

$$
\frac{R_{t}^{L}}{R_{t}}=E_{t}\left\{\frac{1}{\frac{(1-\mu) G\left(\bar{\omega}_{t}^{a}, \sigma_{\omega, t}\right)}{\bar{\omega}_{t}^{a}}+\left[1-F\left(\bar{\omega}_{t}^{a}, \sigma_{\omega, t}\right)\right]}\right\} .
$$

According to equation (4), for a given demand of credit from borrowers, observed values of risk $\sigma_{\omega, t}$, and expected values of the housing stock $E_{t}\left[P_{t+1}^{D} D_{t+1}^{B}\right]$, intermediaries passively set the lending rate $R_{t}^{L}$ and the expected (ex-ante) threshold $\bar{\omega}_{t}^{a}$ so that equation (1) and the participation constraint (2) are fulfilled. Unlike the original BGG set-up, the one-period lending rate $R_{t}^{L}$ is determined at time $t$, and does not depend on the state of the economy at $t+1$. This means that the participation constraint of financial intermediaries delivers ex-ante zero profits. However, it is possible that, ex-post, they make profits or losses. We assume that savers collect profits or recapitalize financial intermediaries as needed. As discussed in Quint and Rabanal (2014), the participation constraint delivers a positive relationship between LTV ratios $\left(S_{t}^{B} / P_{t+1}^{D} D_{t+1}^{B}\right)$ and the spread between the funding and the lending rate, due to the probability of default. 
Finally, we assume that the deposit rate in the home region equals the risk-free rate set by the central bank. In the rest of the euro area, domestic financial intermediaries behave the same way. In their case, they face a deposit rate $R_{t}^{*}$ and a lending rate $R_{t}^{L^{*}}$, and the spread is determined in an analogous way to equation (2). We explain below how the deposit rate in the rest of the euro area $R_{t}^{*}$ is determined.

\section{A.2. International Intermediaries}

International financial intermediaries buy and sell bonds issued by domestic intermediaries in both regions. For instance, if the home domestic intermediaries have an excess $B_{t}$ of loanable funds, they will sell them to the international intermediaries, who will lend an amount $B_{t}^{*}$ to the rest of the euro area domestic intermediaries. International intermediaries apply the following formula to the spread they charge between bonds in the home (issued at an interest rate $R_{t}$ ) and in the rest of the euro area regions (issued at $R_{t}^{*}$ ):

$$
R_{t}^{*}=R_{t}+\left\{\vartheta_{t} \exp \left[\kappa_{B}\left(\frac{B_{t}}{P_{t}^{C} Y^{C}}\right)\right]-1\right\} .
$$

The spread depends on the ratio of real net foreign assets $B_{t} / P_{t}^{C}$ to steady state non-durable $\operatorname{GDP}\left(Y^{C}\right)$ in the home region (to be defined below). When home domestic intermediaries have an excess of funds that they wish to lend to the rest of the euro area domestic intermediaries, then $B_{t}>0$. Hence, the rest of the euro area intermediaries will pay a higher interest rate $R_{t}^{*}>R_{t}$. The parameter $\kappa_{B}$ denotes the risk premium elasticity and $\vartheta_{t}$ is a region-wide risk premium shock, which increases the wedge between the home and the rest of the euro area deposit rates. International intermediaries are owned by savers in each region, and optimality conditions will ensure that the net foreign asset position of both countries is stationary. ${ }^{13}$ They always make positive profits $\left(R_{t}^{*}-R_{t}\right) B_{t}$, which are equally split between savers of both countries.

\section{B. Households}

\section{B.1. Savers}

Savers indexed by $j \in[0, \lambda]$ maximize the following utility function:

$$
E_{0}\left\{\sum_{t=0}^{\infty} \beta^{t}\left[\gamma \xi_{t}^{C} \log \left(C_{t}^{j}-\varepsilon C_{t-1}\right)+(1-\gamma) \xi_{t}^{D} \log \left(D_{t}^{j}\right)-\frac{\left(L_{t}^{j}\right)^{1+\varphi}}{1+\varphi}\right]\right\},
$$

\footnotetext{
${ }^{13}$ Hence, the assumption that international intermediaries trade uncontingent bonds amounts to the same case as allowing savers to trade these bonds. Under market incompleteness, a risk premium function of the type assumed in equation (5) is required for the existence of a well-defined steady state and stationarity of the net foreign asset position. See Schmitt-Grohé and Uribe (2003).
} 
where $C_{t}^{j}, D_{t}^{j}$, and $L_{t}^{j}$ represent the consumption of the flow of non-durable goods, the stock of durable goods (housing) and the labor disutility of agent $j$. Following Smets and Wouters (2003) as well as Iacoviello and Neri (2010) we assume external habit persistence in non-durable consumption, with $\varepsilon$ measuring the influence of past aggregate non-durable consumption $C_{t-1}$. The parameter $\beta$ stands for the discount factor of savers, $\gamma$ measures the share of non-durable consumption in the utility function, and $\varphi$ denotes the inverse elasticity of labor supply.

The utility function is hit by two preference shocks, affecting the marginal utility of either non-durable consumption $\left(\xi_{t}^{C}\right)$ or housing $\left(\xi_{t}^{D}\right)$. As we show in Section IV, the housing demand shock is key to explain the housing and credit boom and bust cycle in some countries of the euro area. This shock can be seen as a short-cut for unmodeled factors affecting the demand of housing, such as population growth and speculative demand for housing. ${ }^{14}$ However, we are not able to take a stand on which factor is the most important one.

Non-durable consumption is an index composed of home $\left(C_{H, t}^{j}\right)$ and rest of the euro area $\left(C_{F, t}^{j}\right)$ produced goods:

$$
C_{t}^{j}=\left[\tau^{\frac{1}{\iota_{C}}}\left(C_{H, t}^{j}\right)^{\frac{{ }^{\iota} C}{{ }^{\iota} C}-1}+(1-\tau)^{\frac{1}{{ }^{\iota} C}}\left(C_{F, t}^{j}\right)^{\frac{\iota_{C} C-1}{{ }^{\iota} C}}\right]^{\frac{\iota_{C} C}{\iota_{C}-1}},
$$

with $\tau \in[0,1]$ denoting the fraction of domestically produced non-durables at home and $\iota_{C}$ governing the substitutability between domestic and rest of the euro area consumption goods. Following Iacoviello and Neri (2010), we introduce imperfect substitutability of labor supply between the durable and non-durable sector to explain comovement at the sector level:

$$
L_{t}^{j}=\left[\alpha^{-\iota_{L}}\left(L_{t}^{C, j}\right)^{1+\iota_{L}}+(1-\alpha)^{-\iota_{L}}\left(L_{t}^{D, j}\right)^{1+\iota_{L}}\right]^{\frac{1}{1+\iota_{L}}}
$$

The labor disutility index consists of hours worked in the non-durable sector $L_{t}^{C, j}$ and durable sector $L_{t}^{D, j}$, with $\alpha$ denoting the share of employment in the non-durable sector. Reallocating labor across sectors is costly, and is governed by the parameter $\iota_{L} \cdot{ }^{15}$

The budget constraint of savers in nominal terms reads:

$$
P_{t}^{C} C_{t}^{j}+P_{t}^{D} I_{t}^{j}+S_{t}^{j} \leq R_{t-1} S_{t-1}^{j}+W_{t}^{C} L_{t}^{C, j}+W_{t}^{D} L_{t}^{D, j}+\Pi_{t}^{j},
$$

where $P_{t}^{C}$ and $P_{t}^{D}$ are the price indices of non-durable and durable goods, respectively, which are defined below. $W_{t}^{C}$ and $W_{t}^{D}$ are nominal wage indices paid in both sectors, as explained below. Savers allocate their expenditures between non-durable consumption $C_{t}^{j}$ and residential investment $I_{t}^{j}$. They have access to deposits in the domestic financial system $S_{t}^{j}$, that pay

\footnotetext{
${ }^{14}$ Adam, Kuang, and Marcet (2011) show that departing from rational expectations and introducing learning mechanisms is important to explain large boom and bust cycles in housing. However, it is not straightforward to introduce learning in a large scale model as ours, and perform Bayesian estimation. Therefore, the housing demand shock can also be seen as a short-cut for departures from rational expectations.

${ }^{15}$ Note that when $\iota_{L}=0$ the aggregator is linear in hours worked in each sector and there are no costs of switching between sectors.
} 
the deposit interest rate $R_{t}$. In addition, savers also receive profits $\Pi_{t}^{j}$ from intermediate goods producers in the durable and the non-durable sector, from domestic and international financial intermediaries, and from debt-collection agencies that charge fees to domestic financial intermediaries to make defaulting households pay their debts.

Purchases of durable goods, or residential investment $I_{t}^{j}$ are used to increase the housing stock $D_{t}^{j}$ with a lag, according to the following law of motion:

$$
D_{t}^{j}=(1-\delta) D_{t-1}^{j}+\left[1-\digamma\left(\frac{I_{t-1}^{j}}{I_{t-2}^{j}}\right)\right] I_{t-1}^{j}
$$

where $\delta$ denotes the depreciation rate of the housing stock and $\digamma(\cdot)$ an adjustment cost function. Following Christiano, Eichenbaum, and Evans $(2005), \digamma(\cdot)$ is a convex function, which in steady state meets the following criteria: $\bar{\digamma}=\bar{\digamma}^{\prime}=0$ and $\bar{\digamma}^{\prime \prime}>0 .{ }^{16}$

\section{B.2. Labor Unions and Wage Setting}

Nominal wages are assumed to be sticky as in Smets and Wouters (2003) and Iacoviello and Neri (2010). Households provide their homogenous labor services to labor unions, which differentiate these services, negotiate wages, and sell them to labor packers afterwards. These perfectly competitive wholesale labor packers reassemble these services into homogenous labor composites and offer them to intermediate goods producers. There exist two unions in each region, one for each sector, which set nominal wages for the respective sector subjected to a Calvo scheme. The probabilities of being able to readjust wages in a given period for the non-durable and durable sector are given by $1-\theta_{C, W}$ and $1-\theta_{D, W}$, respectively. In addition, remaining wages which are not readjusted are partially indexed to past CPI inflation (with the fractions $\varphi_{C, W}$ and $\varphi_{D, W}$, respectively). We assume that wages are the same in the non-durable and durable sector, regardless of the type of households. Unions are run by savers while borrowers are merely members. Thus, unions maximize the utility of savers (6) subject to their budget constraint (9) and to the demand schedule of labor packers. ${ }^{17}$

\section{B.3. Borrowers}

Borrowers differ from savers along three main dimensions. First, their preferences are different. Their discount factor of borrowers is smaller $\left(\beta^{B}<\beta\right)$, and we allow for different habit formation coefficients $\varepsilon^{B}$. Second, borrowers do not earn profits from intermediate goods producers, financial intermediaries, or debt-collection agencies. Finally, as discussed above, borrowers are

\footnotetext{
${ }^{16}$ This cost function allows us to replicate hump-shaped responses of residential investment to shocks, and reduce residential investment volatility.

${ }^{17}$ Borrowers take wages as given and supply labor to both sectors by equating their marginal rate of substitution to that of savers. We assume that the wage mark-up is high enough and shocks are small enough such that both types of workers will always want to supply labor at the prevailing wage.
}

CInternational Monetary Fund. Not for Redistribution 
subject to a quality shock to the value of their housing stock $\omega_{t}^{j}$. Since borrowers are more impatient, in equilibrium, savers are willing to accumulate assets as deposits, and borrowers are willing to pledge their housing wealth as collateral to gain access to loans. Analogously to savers, the utility function for each borrower $j \in[\lambda, 1]$ reads:

$$
E_{0}\left\{\sum_{t=0}^{\infty}\left(\beta^{B}\right)^{t}\left[\gamma \xi_{t}^{C} \log \left(C_{t}^{B, j}-\varepsilon^{B} C_{t-1}^{B}\right)+(1-\gamma) \xi_{t}^{D} \log \left(D_{t}^{B, j}\right)-\frac{\left(L_{t}^{B, j}\right)^{1+\varphi}}{1+\varphi}\right]\right\}
$$

where all variables and parameters with the superscript $B$ denote that they are specific to borrowers. The indices of consumption and hours worked, and the law of motion of the housing stock have the same functional form as in the case of savers (equations 7, 8, and 10). The budget constraint for borrowers differs among those who default and those who repay their loans in full. Hence, aggregating borrowers' budget constraints and dropping the $j$ superscripts, we obtain the following:

$$
\begin{aligned}
P_{t}^{C} C_{t}^{B}+P_{t}^{D}\left[I_{t}^{B}+G\right. & \left.\left(\bar{\omega}_{t-1}^{p}, \sigma_{\omega, t-1}\right) D_{t}^{B}\right]+\left[1-F\left(\bar{\omega}_{t-1}^{p}, \sigma_{\omega, t-1}\right)\right] R_{t-1}^{L} S_{t-1}^{B} \\
\leq & S_{t}^{B}+W_{t}^{C} L_{t}^{C, B}+W_{t}^{D} L_{t}^{D, B} .
\end{aligned}
$$

Borrowers consume non-durables $C_{t}^{B}$, invest in the housing stock $I_{t}^{B}$, and supply labor to both sectors $\left(L_{t}^{C, B}\right.$ and $\left.L_{t}^{D, B}\right)$. Savers and borrowers are paid the same wages $W_{t}^{C}$ and $W_{t}^{D}$ in both sectors. Borrowers take wages (which are bargained by unions owned by savers) as given, and equate them to their marginal rate of substitution between consumption and hours in each sector.

Borrowers obtain loans $S_{t}^{B}$ from financial intermediaries at a lending rate $R_{t}^{L}$. After aggregate and idiosyncratic shocks hit the economy, borrowers will default if the realization of the idiosyncratic shock falls below the ex-post threshold:

$$
\bar{\omega}_{t-1}^{p}=\frac{R_{t-1}^{L} S_{t-1}^{B}}{P_{t}^{D} D_{t}^{B}} .
$$

Since investment increases the housing stock with a lag (equation 10), $D_{t}^{B}$ is a pre-determined variable. The lending rate is also pre-determined and not a function of the state of the economy. So it is possible that $\bar{\omega}_{t}^{a}$ and $\bar{\omega}_{t}^{p}$ differ. Note, however, that when the loan is signed, $\bar{\omega}_{t}^{a}=E_{t} \bar{\omega}_{t}^{p}$. The term $\left[1-F\left(\bar{\omega}_{t-1}^{p}, \sigma_{\omega, t-1}\right)\right]=\int_{\bar{\omega}_{t-1}^{p}}^{\infty} d F\left(\omega ; \sigma_{\omega, t-1}\right) d \omega$ defines the fraction of loans which are repaid by the borrowers, because they were hit by a realization of the shock above the threshold $\bar{\omega}_{t-1}^{p}$. Similarly, $P_{t}^{D} G\left(\bar{\omega}_{t-1}^{p}, \sigma_{\omega, t-1}\right) D_{t}^{B}=P_{t}^{D} \int_{0}^{\bar{\omega}_{t-1}^{p}} \omega d F\left(\omega ; \sigma_{\omega, t-1}\right) D_{t}^{B}$ is the value of the housing stock on which borrowers have defaulted on and which is paid to banks after a debt-collection agency intervenes. 


\section{Firms, Technology, and Sticky Prices}

Homogeneous final non-durable and durable goods are produced using a continuum of intermediate goods in each sector (indexed by $h \in[0, n]$ in the home region, and by $f \in[n, 1]$ in the rest of the euro area region). Intermediate goods in each sector are imperfect substitutes of each other, and there is monopolistic competition as well as Calvo (1983)-style staggered price setting. Intermediate goods are not traded across regions and are bought by domestic final goods producers. In the final goods sector, non-durables are sold to domestic and rest of the euro area households. ${ }^{18}$ Durable goods are solely sold to domestic households, who use them to increase the housing stock. Both final goods sectors are perfectly competitive, operating under flexible prices.

\section{C.1. Final Goods Producers}

Final goods producers in both sectors aggregate the intermediate goods they purchase according to the following production function:

$$
Y_{t}^{k} \equiv\left[\left(\frac{1}{n}\right)^{\frac{1}{\sigma_{k_{t}}}} \int_{0}^{n} Y_{t}^{k}(h)^{\frac{\sigma_{k_{t}}-1}{\sigma_{k_{t}}}} d h\right]^{\frac{\sigma_{k_{t}}}{\sigma_{k_{t}}-1}}, \text { for } k=C, D
$$

where $Y_{t}^{k}$ represents the final goods produced from intermediate goods $Y_{t}^{k}(h)$, while $\sigma_{k_{t}}$ denotes the price elasticity of intermediate goods, which is time-varying because there are $i$ id price markup shocks. Final goods producers purchase non-durable intermediate goods at a price of $P_{t}^{H}(h)$ and durable intermediate goods at a price $P_{t}^{D}(h)$. Profit maximization leads to the following demand function for individual intermediate goods:

$$
Y_{t}^{C}(h)=\left(\frac{P_{t}^{H}(h)}{P_{t}^{H}}\right)^{-\sigma_{C_{t}}} Y_{t}^{H}, \text { and } Y_{t}^{D}(h)=\left(\frac{P_{t}^{D}(h)}{P_{t}^{D}}\right)^{-\sigma_{D_{t}}} Y_{t}^{D} .
$$

Price levels for domestically produced non-durables $P_{t}^{H}$ and durable final goods $P_{t}^{D}$ are obtained through the usual zero-profit condition:

$$
P_{t}^{H} \equiv\left\{\frac{1}{n} \int_{0}^{n}\left[P_{t}^{H}(h)\right]^{1-\sigma_{C_{t}}} d h\right\}^{\frac{1}{1-\sigma_{C_{t}}}}, \text { and } P_{t}^{D} \equiv\left\{\frac{1}{n} \int_{0}^{n}\left[P_{t}^{D}(h)\right]^{1-\sigma_{D_{t}}} d h\right\}^{\frac{1}{1-\sigma_{D_{t}}}} .
$$

The price level for non-durables consumed in the home region (i.e. the CPI for the home region) includes the price of domestically produced non-durables $\left(P_{t}^{H}\right)$, and of imported non-durables $\left(P_{t}^{F}\right)$ :

$$
P_{t}^{C}=\left[\tau\left(P_{t}^{H}\right)^{1-\iota_{C}}+(1-\tau)\left(P_{t}^{F}\right)^{1-\iota_{C}}\right]^{\frac{1}{1-\iota_{C}}}
$$

\footnotetext{
${ }^{18}$ Thus, for non-durable consumption we need to distinguish between the price level of domestically produced non-durable goods $P_{H, t}$, of non-durable goods produced abroad $P_{F, t}$, and the consumer price index $P_{t}^{C}$, which will be a weighted combination of these two price levels.
} 


\section{C.2. Intermediate Goods Producers}

Intermediate goods are produced under monopolistic competition with producers facing Calvostyle staggered price setting, which implies that in each period only a fraction $1-\theta_{C}\left(1-\theta_{D}\right)$ of intermediate goods producers in the non-durable (durable) sector receive a signal to re-optimize their price. For the remaining fraction $\theta_{C}\left(\theta_{D}\right)$ we assume that their prices are partially indexed to lagged sector-specific inflation (with a coefficient $\phi_{C}, \phi_{D}$ in each sector). In both sectors, intermediate goods are produced solely with labor:

$$
Y_{t}^{C}(h)=A_{t} Z_{t}^{C} L_{t}^{C}(h), \quad Y_{t}^{D}(h)=A_{t} Z_{t}^{D} L_{t}^{D}(h) \text { for all } h \in[0, n]
$$

The production functions include region- and sector-specific stationary technology shocks $Z_{t}^{C}$ and $Z_{t}^{D}$, each of which follows a zero mean $\operatorname{AR}(1)$-process in logs. In addition, we introduce a non-stationary union-wide technology shock, which follows a unit root process:

$$
\log \left(A_{t}\right)=\log \left(A_{t-1}\right)+\varepsilon_{t}^{A} .
$$

This shock introduces non-stationarity to the model and constitutes a model-consistent way of detrending the data by taking logs and first differences to the real variables that inherit the random-walk behavior. In addition, it adds some correlation of technology shocks across sectors and countries, which is helpful from the empirical point of view because it allows to explain comovement of main real variables. Since labor is the only production input, cost minimization implies that real marginal costs in both sectors are given by:

$$
M C_{t}^{C}=\frac{W_{t}^{C} / P_{H, t}}{A_{t} Z_{t}^{C}}, \quad M C_{t}^{D}=\frac{W_{t}^{D} / P_{t}^{D}}{A_{t} Z_{t}^{D}} .
$$

Intermediate goods producers solve a standard Calvo model profit maximization problem with indexation. As shown in the appendix, inflation dynamics in each sector depend on one expected lead and one lag of inflation, and the sector-specific real marginal cost. We assume the there are price mark-ups in the non-durable price level (CPI), such that $\mu_{C_{t}}=\frac{\sigma_{C_{t}}}{\sigma_{C_{t}}-1}=\mu_{C} \exp \left(\varepsilon_{\mu_{C_{t}}}\right)$, where the innovation (price mark-up shock) is iid. This shock is intended to pick up high frequency movements in the consumer price level in both countries, due to unmodelled volatile factors such as energy and food prices.

\section{Closing the Model}

\section{D.1. Market Clearing Conditions}

For intermediate goods, supply equals demand. We write the market clearing conditions in terms of aggregate quantities and, thus, multiply per-capita quantities by population size of each region. In the home non-durable sector, production is equal to domestic demand by savers $C_{H, t}$ and borrowers $C_{H, t}^{B}$ and exports (consisting of demand by savers $C_{H, t}^{*}$ and borrowers $C_{H, t}^{B^{*}}$ 
from the rest of the euro area region):

$$
n Y_{t}^{C}=n\left[\lambda C_{H, t}+(1-\lambda) C_{H, t}^{B}\right]+(1-n)\left[\lambda^{*} C_{H, t}^{*}+\left(1-\lambda^{*}\right) C_{H, t}^{B^{*}}\right] .
$$

Durable goods are only consumed by domestic households and production in this sector is equal to residential investment for savers and borrowers:

$$
n Y_{t}^{D}=n\left[\lambda I_{t}+(1-\lambda) I_{t}^{B}\right] .
$$

In the labor market, total hours worked has to be equal to the aggregate supply of labor in each sector by both savers and borrowers:

$$
\int_{0}^{n} L_{t}^{k}(h) d h=\lambda \int_{0}^{n} L_{t}^{k, j} d j+(1-\lambda) \int_{0}^{n} L_{t}^{k, B, j} d j, \text { for } k=C, D .
$$

Credit market clearing implies that for domestic credit and international bond markets, the balance sheets of financial intermediaries are satisfied. Besides equation (3), this requires:

$$
n \lambda B_{t}+(1-n) \lambda^{*} B_{t}^{*}=0 .
$$

Finally, aggregating the resource constraints of borrowers and savers, and the market clearing conditions for goods and financial intermediaries, we obtain the law of motion of bonds issued by the home international financial intermediaries. This can also be viewed as the evolution of net foreign assets (NFA) of the home region:

$$
\begin{aligned}
n \lambda B_{t}= & n \lambda R_{t-1} B_{t-1} \\
& +\left\{(1-n) P_{H, t}\left[\lambda^{*} C_{H, t}^{*}+\left(1-\lambda^{*}\right) C_{H, t}^{B^{*}}\right]-n P_{F, t}\left[\lambda C_{F, t}+(1-\lambda) C_{F, t}^{B}\right]\right\},
\end{aligned}
$$

which is determined by the aggregate stock of last period's NFA times the interest rate, plus net exports.

\section{D.2. Monetary Policy and Interest Rates}

Monetary policy is conducted at the currency union level by the central bank with an interest rate rule that targets deviations of the union-wide CPI inflation and real output growth from their steady-state values. The central bank sets the deposit rate in the home region, and the other rates are determined as described in the model. Let $\bar{\Pi}^{E M U}$ be the steady state level of union-wide CPI inflation, $\bar{R}$ the steady state level of the interest rate and $\varepsilon_{t}^{m}$ an iid monetary policy shock, the interest rate rule is given by:

$$
R_{t}=\left[\bar{R}\left(\frac{P_{t}^{E M U} / P_{t-1}^{E M U}}{\bar{\Pi}^{E M U}}\right)^{\gamma_{\pi}}\left(Y_{t}^{E M U} / Y_{t-1}^{E M U}\right)^{\gamma_{y}}\right]^{1-\gamma_{R}} R_{t-1}^{\gamma_{R}} \exp \left(\varepsilon_{t}^{m}\right) .
$$


The euro area CPI $\left(P_{t}^{E M U}\right)$ and real GDP $\left(Y_{t}^{E M U}\right)$ are given by geometric averages of the home and rest of the euro area region variables, using the region size as a weight:

$$
P_{t}^{E M U}=\left(P_{t}^{C}\right)^{n}\left(P_{t}^{C^{*}}\right)^{1-n}, \text { and } Y_{t}^{E M U}=\left(Y_{t}\right)^{n}\left(Y_{t}^{*}\right)^{1-n} .
$$

where the national real GDPs are expressed in terms of non-durables:

$$
Y_{t}=Y_{t}^{C}+Y_{t}^{D} \frac{P_{t}^{D}}{P_{t}^{C}} \text {, and } Y_{t}^{*}=Y_{t}^{C^{*}}+Y_{t}^{D^{*}} \frac{P_{t}^{D^{*}}}{P_{t}^{C^{*}}} .
$$

\section{Parameter Estimates}

We apply standard Bayesian methods to estimate the parameters of the model (see An and Schorfheide, 2007). First, the equilibrium conditions of the model are normalized such that all real variables become stationary. This is achieved by dividing real variables in both countries by the level of non-stationary technology, $A_{t}$. Second, the dynamics of the model are obtained by taking a log-linear approximation of equilibrium conditions around the steady state with zero inflation and net foreign asset positions. ${ }^{19}$ Third, the solution of the model is expressed in state-space form and the likelihood function of the model is computed using a Kalman filter recursion. Then, we combine the prior distribution over the model's parameters with the likelihood function and apply the Metropolis-Hastings algorithm to obtain the posterior distribution to the model's parameters. ${ }^{20}$

\section{A. Data}

Data for the core (home) region is obtained by aggregating data for France and Germany, whereas the HBS (rest of euro area) region, as discussed in Section 1, includes Greece, Ireland, Italy, Portugal, and Spain. We follow this classification because the HBC countries experienced a similar shock after entering the EMU (the large decline in risk premia and interest rates), and exhibited a somewhat similar behavior in borrowing spreads in the run-up and after the GFC. However, this is not a homogeneous group and each country is different in some aspects. Ireland experienced a smaller decline of borrowing costs when joining the euro, yet it went through a housing and credit boom and bust cycle as much as Spain did. Portugal had a credit boom, but growth was never as high as Greece, Ireland and Spain. Italy's credit boom was milder than the rest, and it displayed lower growth than the rest during the 2000s. Greece's problems started with the fiscal sector, rather than with a housing bust.

We use quarterly data ranging from 2000q1-2013q4 and thirteen macroeconomic time series. Hence, unlike other estimated DSGE models of the euro area, such as Smets and Wouters (2003),

\footnotetext{
${ }^{19}$ Appendix B details the full set of normalized, linearized equilibrium conditions of the model.

${ }^{20}$ The estimation is done using Dynare 4.3.2. The posterior distributions are based on 250,000 draws of the Metropolis-Hastings algorithm.
} 
we do not mix the sample periods before and after the creation of the euro. For both regions we use six observables: real private consumption spending, real residential investment, real gross domestic product (GDP), the harmonized index of consumer prices (HICP), housing prices, and outstanding debt for households. We also include the 3-month Euribor rate, which we use as counterpart of the deposit rate in the core. ${ }^{21}$ The data is aggregated taking the economic size of the countries into account, using the household expenditure weights used by the Harmonised Index of Consumer Prices (HICP) for euro area countries. ${ }^{22}$ We use quarterly growth rates of all price and quantity (seasonally adjusted) data and we divide the interest rates by 400 to obtain a quarterly and logged equivalent variable to the model. We demean all series. ${ }^{23}$

The measure of GDP in the model and in the data is different. In particular, the measure of GDP in the model only includes non-durable consumption and residential investment. Hence, the model leaves out business investment, government spending and net exports with third countries. As a result, we include an aggregate demand shock that collects all these components. In log-linear form this can be written as:

$$
g d p_{t}=(1-\bar{g}) y_{t}+\bar{g}\left(g_{t}\right)
$$

where $\bar{g}$ is the steady state ratio of exogenous demand to GDP, and $g_{t}$ is an exogenous $\operatorname{AR}(1)$ process. ${ }^{24}$

\section{B. Calibrated Parameters}

Some parameters are calibrated because the set of observable variables that we use does not provide information to estimate them (Table 1 ). We assume that the discount factors are the same in both countries for each type of agent $\left(\beta=\beta^{*}\right.$ and $\left.\beta^{B}=\beta^{B^{*}}\right)$. We set the discount factor of savers to $\beta=0.99$. The steady state LTV ratio, which also determines the cut-off point for defaulting on a loan, is set to $\bar{\omega}=0.7$ and equally across regions, according to euro area data such as Gerali et al. (2010). We set the default rate on loans, $\bar{F}($.$) to 2.5$ percent. $^{25}$

\footnotetext{
${ }^{21}$ See Appendix A for further details on the data set.

${ }^{22} \mathrm{http} / /$ www.ecb.europa.eu/stats/prices/hicp/html/hicp_coicop_inw_000000.4.U2W.en.html

${ }^{23} \mathrm{We}$ tried to to include spreads between lending and deposit rates in both regions as an observable variable, but we did not get sensible results. The data available from the ECB confirms that in a credit bust, quantities adjust instead of prices, and hence contain more information about credit conditions. In addition, the ECB's actions after the crisis (including the Long Term Refinancing Operations) have helped reduce lending-deposit spreads in the countries that initially faced high borrowing costs during 2010-2011, and have thus reduced the information content of the spreads.

${ }^{24}$ We include business investment in this definition, but this variable affects labor productivity through capital deepening. Hence, when we decompose the contribution of individual shocks on the observable variables and the output gap in Section 4, we deduct the share of business investment ((Business Investment)/(Business Investment + Government Spending + Net Exports $)$ ) from the aggregate demand shock and include it in the technology shock. To do this transformation, we use annual data on net exports, government expenditure and business investment from the OECD database. We aggregate the data using the same weights and methodology that we described earlier in this section.

${ }^{25}$ It is difficult to find non-perfoming loans for household mortgages only. Therefore, we use non-performing loans as percent of total loans for the euro area between 2000-2011 taken from the World Bank World Develop-
} 
Table 1: Calibrated Parameters

\begin{tabular}{lll}
\hline \hline & & \\
$\beta$ & Discount factor savers & 0.99 \\
$\bar{\omega}$ & Loan-to-value ratio & 0.7 \\
$\bar{F}$ & Default rate on loans & 0.025 \\
$\bar{\sigma}_{\omega}$ & Steady state risk & 0.1742 \\
$\mu$ & Proportion of housing value paid to debt-collection agency & 0.2 \\
$\beta^{B}$ & Discount factor borrowers & 0.985 \\
$\delta$ & Depreciation rate & 0.0125 \\
$\sigma$ & Elasticity of substitution between intermediate goods & 10 \\
$\sigma_{L}$ & Elasticity of substitution between labor types & 10 \\
$n$ & Size core economies & 0.6 \\
$\bar{g}$ & Fraction of exogenous demand in GDP & 0.3 \\
$1-\tau$ & Fraction of imported goods from HBS to core economies & 0.06 \\
$1-\tau^{*}$ & Fraction of imported goods from core to HBS economies & 0.09 \\
$\alpha$ & Size of non-durable sector in GDP & 0.94 \\
& & \\
\hline \hline
\end{tabular}

As a result, the steady state value of the risk shock is $\bar{\sigma}_{\omega}=0.1742$. We set the debt-collection agency fee to $\mu=0.2$, which is a value higher than that calibrated by Forlati and Lambertini (2010), but lower than the recovery rates for loans estimated for the United States. ${ }^{26}$ Using these values, the zero-profit condition for financial intermediaries, and the consumption Euler equation for borrowers, we obtain a discount factor of borrowers of $\beta^{B}=0.985$.

The depreciation rate is assumed to be 5 percent (annual) and equal across countries $(\delta=$ $\left.\delta^{*}=0.0125\right)$. The degree of monopolistic competition in the goods markets $\sigma$ and in the labor markets $\left(\sigma_{L}\right)$ is the same across sectors and countries, implying mark-ups of 10 percent. We set the size of the core countries in the euro area to $n=0.6$, based on GDP data. We set the steady-state ratio of exogenous demand to $\operatorname{GDP}\left(\bar{g}=\bar{g}^{*}\right)$ to 0.3 . The bilateral trade parameter $1-\tau$ is calibrated based on the weighted average of total imports to private consumption from HBS to core economies. The analogous parameter for the HBS countries $1-\tau^{*}$ is calculated in a similar way, but is rounded to ensure that the trade balance and the net foreign asset position are zero in the steady state. Finally, we assume that the size of the durable and nondurable sectors is the same for the core and the HBS countries of the euro area $\left(\alpha=\alpha^{*}\right)$. The assumptions of symmetry and balanced trade make it easier to compute a steady state where all relative prices in all sectors are equal to one, and where all per capita quantities are the same.

ment Indicators database (http://data.worldbank.org/topic/financial-sector).

${ }^{26}$ See Mortgage Bankers Association (2008). 


\section{Prior and Posterior Distributions}

In Table 2 we present the prior distributions, the posterior mean and 90 percent credible set of the economic estimated parameters. ${ }^{27}$ In Table 3, we present the estimated parameters of the shock processes. Given the short sample, in addition to calibrating some parameters, we restrict others to be the same across countries. More specifically, we allow the parameters related to nominal rigidities and shocks to differ across sectors and countries, in order to permit quantitatively different transmission channels of monetary policy. However, the parameters relating to preferences, adjustment costs, and the fraction of savers are assumed to be the same in both countries. As in Quint and Rabanal (2014), we assume that the housing demand shock and the TFP shock in non-durables has a common component across countries. For instance, the housing demand shock follows:

$$
\begin{aligned}
\log \left(\xi_{t}^{D}\right) & =\rho_{\xi, D} \log \left(\xi_{t-1}^{D}\right)+\varepsilon_{t}^{\xi, D}+\varepsilon_{t}^{\xi, D, C O M} \\
\log \left(\xi_{t}^{D^{*}}\right) & =\rho_{\xi, D}^{*} \log \left(\xi_{t-1}^{D^{*}}\right)+\varepsilon_{t}^{\xi, D^{*}}+\varepsilon_{t}^{\xi, D, C O M}
\end{aligned}
$$

where the region-specific $\left(\varepsilon_{t}^{\xi, D}\right.$ and $\left.\varepsilon_{t}^{\xi, D^{*}}\right)$ as well as common $\left(\varepsilon_{t}^{\xi, D, C O M}\right)$ innovations are Normal iid with mean zero. This helps explain the cross correlation of prices and quantities across countries.

First, we comment on the parameters that relate to preferences of borrowers and savers. We opt for a prior distribution centered at 0.5 for the fraction of savers in the economy. We set a highly informative prior by setting a small standard deviation of 0.05 . The posterior mean suggests a somewhat higher fraction $(0.57)$ to fit the macro data. ${ }^{28}$ We make a simplifying assumption that the number of savers in each region $(\lambda)$ is the same in both regions. ${ }^{29}$ Interestingly, we find that the habit formation coefficient is roughly the same ( 0.71 for borrowers and 0.63 for savers). We center the priors related to the elasticity of substitution between home and rest of the euro area non-durables, the elasticity of labor supply and the coefficient measuring costly labor reallocation to parameters available in the literature (Smets and Wouters, 2003; Iacoviello and Neri, 2010; and Adolfson et al., 2007). We find an elasticity of substitution between home and rest of the euro area goods close to the prior (a posterior mean of 1.50, just like the prior mean). Regarding the coefficients that determine labor supply, we find that the posterior mean of the labor disutility coefficient $\varphi$ is 1.14 and the degree of costly labor reallocation is about 0.63 .

\footnotetext{
${ }^{27}$ For each step of the Metropolis-Hastings algorithm, given a draw of the parameters that we wish to estimate, we must solve for the steady state levels of consumption of durables and non-durables, hours worked in each sector by each type of agent, and for each region. Then, these steady state values are needed to obtain the log-linear dynamics to the system. Also, for every draw, we solve for the weight of non-durables in the utility function in each region $\left(\gamma\right.$ and $\left.\gamma^{*}\right)$, which is not a free parameter but rather a function of $\alpha, \delta, \lambda, \beta, \beta^{B}, \varepsilon, \varepsilon^{B}$, and $\varphi$.

${ }^{28}$ Gerali et al. (2010) calibrate this fraction to be 0.8 for the euro area.

${ }^{29}$ Ideally, we would want to estimate a different $\lambda$, for each region. This heterogeneity complicates computing the steady state of the model for each iteration of the Metropolis-Hastings algorithm, and critically slows down the estimation process.
} 
The coefficients on the Taylor rule suggest a moderate response to inflation fluctuations in the euro area (coefficient of 1.34, below the prior mean), a moderate response to real GDP growth (posterior mean of 0.31) and a high degree of interest rate inertia (0.84). We opt for a gamma prior for the risk premia elasticity $\kappa_{B}$ between countries with a mean of 0.01 . We find that the risk premium elasticity between countries moves about 0.6 basis points with a one percent increase in the external debt-to-GDP ratio.

Next, we comment on the coefficients regarding nominal rigidities in price and wage setting. ${ }^{30}$ We opt for Beta prior distributions for all Calvo probabilities with a mean of 0.75 (average duration of price and wage contracts of four quarters). We opt for more informative priors for the wage setting parameters than for the price setting parameters (prior standard deviation of 0.05 for wages and 0.15 for prices). We set the mean of the prior distributions for all indexation parameters to 0.33. This set of priors is consistent with the survey evidence on price-setting presented in Fabiani et al. (2006) and Knell (2013). We find more price rigidity in the nondurable sector, with higher Calvo loteries than in the durable sector, and which are similar across countries. Prices are reset about every 10 quarters in the non-durable sector and about 2 quarters in the durable sector. Wage rigidity is similar across countries and sectors, which average wage durations between roughly 4 and 6 quarters. This result could be due to the fact that we are not using wage data and hence posteriors are not too different from priors. We find that both price and wage indexation is low in all prices and sectors.

Regarding the prior and posterior distributions for the shock processes, we comment on two main results. First, the common innovations to non-durable technology shocks and durable preference shocks are important. Second, the mean of the $(\log )$ risk shock is $\log (0.1742)=$ -1.74 . We set a prior standard deviation for the innovation to the housing risk shock of 0.25 (that is, 25 percent), such that, roughly, the two-standard deviation prior interval is between 1.25 and -2.25 . Given the properties of the log-normal distribution, this means that the default rate for mortgages ranges between 0.04 and 13.6 percent with 95 percent probability. This seems to be an acceptable range for euro area member states. ${ }^{31}$ The estimates for the variance of the quality shock in the HBS countries are smaller than the prior, while in the core there seems to be much less risk volatility, as reflected by the posterior.

\footnotetext{
${ }^{30}$ We do not use sectoral wage data that would allow for a better identification of the parameters of the wage Phillips curves. We still estimate these parameters, rather than calibrating them, to improve overall model fit.

${ }^{31}$ See the World Development Indicators database from the World Bank.
} 
Table 2: Prior and Posterior Distributions, Economic Parameters

\begin{tabular}{|c|c|c|c|c|c|c|}
\hline & \multirow[b]{2}{*}{ Common Parameters } & \multicolumn{3}{|c|}{ Prior } & \multicolumn{2}{|c|}{ Posterior } \\
\hline & & & Mean & $\mathrm{SD}$ & Mean & $90 \%$ C.S. \\
\hline$\lambda$ & Fraction of savers & Beta & 0.5 & 0.05 & 0.57 & {$[0.50,0.64]$} \\
\hline$\varepsilon$ & Habit formation savers & Beta & 0.5 & 0.15 & 0.71 & {$[0.65,0.78]$} \\
\hline$\varepsilon^{B}$ & Habit formation borrowers & Beta & 0.5 & 0.15 & 0.63 & {$[0.52,0.73]$} \\
\hline$\varphi$ & Labor disutility & Gamma & 1 & 0.5 & 1.14 & {$[0.75,1.53]$} \\
\hline$\iota_{C}$ & Elasticity of subst. between goods & Gamma & 1.5 & 0.5 & 1.50 & {$[0.86,2.17]$} \\
\hline$\iota_{L}$ & Labor reallocation costs & Gamma & 1 & 0.5 & 0.66 & {$[0.42,0.83]$} \\
\hline$\psi$ & Investment adjustment costs & Gamma & 2 & 1 & 1.94 & {$[1.31,2.55]$} \\
\hline$\gamma_{\pi}$ & Taylor rule reaction to inflation & Normal & 1.5 & 0.1 & 1.34 & {$[1.16,1.50]$} \\
\hline$\gamma_{y}$ & Taylor rule reaction to real growth & Gamma & 0.2 & 0.05 & 0.29 & {$[0.19,0.41]$} \\
\hline$\gamma_{r}$ & Interest rate smoothing & Beta & 0.66 & 0.15 & 0.84 & {$[0.81,0.87]$} \\
\hline$\kappa_{B}$ & International risk premium & Gamma & 0.005 & 0.002 & 0.006 & {$[0.002,0.009]$} \\
\hline & Region-Specific Parameters & & & & & \\
\hline$\theta_{C}$ & Calvo lottery, price non-durables & Beta & 0.75 & 0.15 & 0.87 & {$[0.82,0.92]$} \\
\hline$\theta_{C}^{*}$ & Calvo lottery, price non-durables & Beta & 0.75 & 0.15 & 0.93 & {$[0.89,0.97]$} \\
\hline$\theta_{D}$ & Calvo lottery, price durables & Beta & 0.75 & 0.15 & 0.50 & {$[0.39,0.61]$} \\
\hline$\theta_{D}^{*}$ & Calvo lottery, price durables & Beta & 0.75 & 0.15 & 0.43 & {$[0.31,0.54]$} \\
\hline$\phi_{C}$ & Indexation, price non-durables & Beta & 0.33 & 0.15 & 0.16 & {$[0.03,0.28]$} \\
\hline$\phi_{C}^{*}$ & Indexation, price non-durables & Beta & 0.33 & 0.15 & 0.30 & {$[0.13,0.47]$} \\
\hline$\phi_{D}$ & Indexation, price durables & Beta & 0.33 & 0.15 & 0.14 & {$[0.02,0.25]$} \\
\hline$\phi_{D}^{*}$ & Indexation, price durables & Beta & 0.33 & 0.15 & 0.20 & {$[0.03,0.36]$} \\
\hline$\theta_{W, C}$ & Calvo lottery, wage non-durables & Beta & 0.75 & 0.15 & 0.69 & {$[0.62,0.77]$} \\
\hline$\theta_{W, C}^{*}$ & Calvo lottery, wage non-durables & Beta & 0.75 & 0.15 & 0.83 & {$[0.79,0.87]$} \\
\hline$\theta_{W, D}$ & Calvo lottery, wage durables & Beta & 0.75 & 0.15 & 0.78 & {$[0.71,0.85]$} \\
\hline$\theta_{W, D}^{*}$ & Calvo lottery, wage durables & Beta & 0.75 & 0.15 & 0.77 & {$[0.72,0.82]$} \\
\hline$\phi_{W, C}$ & Indexation, wage non-durables & Beta & 0.33 & 0.15 & 0.26 & {$[0.06,0.47]$} \\
\hline$\phi_{W, C}^{*}$ & Indexation, wage non-durables & Beta & 0.33 & 0.15 & 0.29 & {$[0.06,0.51]$} \\
\hline$\phi_{W, D}$ & Indexation, wage durables & Beta & 0.33 & 0.15 & 0.27 & {$[0.06,0.47]$} \\
\hline$\phi_{W, D}^{*}$ & Indexation, wage durables & Beta & 0.33 & 0.15 & 0.28 & {$[0.06,0.48]$} \\
\hline
\end{tabular}

Note: Parameters with an asterisk are the HBS countries' counterpart to the same parameter in the core. C.S. denotes confidence set. 
Table 3: Prior and Posterior Distributions, AR(1) Shock Processes

\begin{tabular}{|c|c|c|c|c|c|c|}
\hline & \multirow{2}{*}{$\begin{array}{l}\text { Parameters } \\
\operatorname{AR}(1) \text { coefficients }\end{array}$} & \multicolumn{3}{|c|}{ Prior } & \multicolumn{2}{|c|}{ Posterior } \\
\hline & & & Mean & S.D. & Mean & 90\% C.S. \\
\hline$\rho_{Z, C}$ & Technology, non-durables & Beta & 0.7 & 0.1 & 0.76 & {$[0.67,0.84]$} \\
\hline$\rho_{Z, D}$ & Technology, durables & Beta & 0.7 & 0.1 & 0.86 & {$[0.79,0.94]$} \\
\hline$\rho_{Z, C}^{*}$ & Technology, non-durables & Beta & 0.7 & 0.1 & 0.81 & {$[0.68,0.93]$} \\
\hline$\rho_{Z, D}^{*}$ & Technology, durables & Beta & 0.7 & 0.1 & 0.72 & {$[0.56,0.87]$} \\
\hline$\rho_{\xi, C}$ & Preference, non-durables & Beta & 0.7 & 0.1 & 0.70 & {$[0.58,0.83]$} \\
\hline$\rho_{\xi, D}$ & Preference, durables & Beta & 0.7 & 0.1 & 0.96 & {$[0.94,0.98]$} \\
\hline$\rho_{\xi, C}^{*}$ & Preference, non-durables & Beta & 0.7 & 0.1 & 0.73 & {$[0.58,0.89]$} \\
\hline$\rho_{\xi, D}^{*}$ & Preference, durables & Beta & 0.7 & 0.1 & 0.98 & {$[0.97,0.99]$} \\
\hline$\rho_{\omega}$ & Risk shock, durables & Beta & 0.7 & 0.1 & 0.74 & {$[0.61,0.87]$} \\
\hline$\rho_{\omega}^{*}$ & Risk shock, durables & Beta & 0.7 & 0.1 & 0.74 & {$[0.65,0.82]$} \\
\hline$\rho_{G}$ & Demand shock & Beta & 0.7 & 0.1 & 0.79 & {$[0.71,0.88]$} \\
\hline$\rho_{G}^{*}$ & Demand shock & Beta & 0.7 & 0.1 & 0.48 & {$[0.38,0.60]$} \\
\hline \multirow[t]{2}{*}{$\rho_{\vartheta}$} & Risk premium, core-HBS & Beta & 0.7 & 0.1 & 0.87 & {$[0.82,0.92]$} \\
\hline & Standard Deviation Shocks & & & & & \\
\hline$\sigma_{A}$ & Technology, EMU-wide & Gamma & 0.7 & 0.2 & 0.65 & {$[0.49,0.81]$} \\
\hline$\sigma_{C, Z}$ & Technology, non-durables & Gamma & 0.7 & 0.2 & 0.97 & {$[0.62,1.32]$} \\
\hline$\sigma_{C^{*}, Z}$ & Technology, non-durables & Gamma & 0.7 & 0.2 & 0.77 & {$[0.43,1.09]$} \\
\hline$\sigma_{C, Z}^{C O M}$ & Technology, non-durables, common & Gamma & 0.7 & 0.2 & 0.85 & {$[0.50,1.20]$} \\
\hline$\sigma_{D, Z}$ & Technology, durables & Gamma & 0.7 & 0.2 & 1.09 & {$[0.78,1.41]$} \\
\hline$\sigma_{D^{*}, Z}$ & Technology, durables & Gamma & 0.7 & 0.2 & 0.85 & {$[0.56,1.16]$} \\
\hline$\sigma_{C, \xi}$ & Preference, non-durables & Gamma & 1 & 0.5 & 2.10 & {$[1.55,2.58]$} \\
\hline$\sigma_{C^{*}, \xi}$ & Preference., non-durables & Gamma & 1 & 0.5 & 0.75 & {$[0.27,1.23]$} \\
\hline$\sigma_{D, \xi}$ & Preference, durables & Gamma & 1 & 0.5 & 4.63 & {$[2.99,6.19]$} \\
\hline$\sigma_{D^{*}, \xi}$ & Preference, durables & Gamma & 1 & 0.5 & 3.67 & {$[2.54,4.93]$} \\
\hline$\sigma_{D, \xi}^{C O M}$ & Preference, durables, common & Gamma & 1 & 0.5 & 1.55 & {$[0.48,2.52]$} \\
\hline$\sigma_{\mu^{C}}$ & Mark-up, non-durable prices & Gamma & 1 & 0.5 & 0.23 & {$[0.17,0.29]$} \\
\hline$\sigma_{\mu} C^{*}$ & Mark-up, non-durable prices & Gamma & 1 & 0.5 & 0.30 & {$[0.24,0.36]$} \\
\hline$\sigma_{G}$ & Demand & Gamma & 1 & 0.5 & 1.47 & {$[1.21,1.72]$} \\
\hline$\sigma_{G^{*}}$ & Demand & Gamma & 1 & 0.5 & 0.97 & {$[0.79,1.17]$} \\
\hline$\sigma_{m}$ & Monetary & Gamma & 0.4 & 0.2 & 0.11 & {$[0.1,0.14]$} \\
\hline$\sigma_{\vartheta}$ & Risk premium & Gamma & 0.4 & 0.2 & 0.26 & {$[0.15,0.35]$} \\
\hline$\sigma_{u_{\omega}}$ & Risk shock & Gamma & 25 & 12.5 & 12.9 & {$[9.74,15.88]$} \\
\hline$\sigma_{u_{\omega}^{*}}$ & Risk shock & Gamma & 25 & 12.5 & 33.47 & {$[27.13,39.42]$} \\
\hline
\end{tabular}

Note: Parameters with an asterisk are the HBS countries' counterpart to the same parameter in the core. C.S. denotes confidence set. 


\section{Variance Decomposition: The Role of Demand and Financial Shocks}

In Table 4 we provide the shock decomposition of several variables of interest at the posterior mode. $^{32}$ For each region, we decompose the contribution of several types of shocks to the following variables: (detrended) output, output gap, inflation, credit and house prices. In addition, we report the shock decomposition of the euro area output gap and CPI inflation. In order to facilitate the reading of the variance decomposition exercise, we aggregate shocks across regions for each category. For instance, the "Markups" label aggregates price markup shocks in both regions of the euro area. The "Housing Preference" label aggregates the regionspecific and common housing preference shocks. We also consolidate the effects of all regionand sector-specific technology shocks, as well as the innovation to the permanent technology shock and the common component of the non-durable productivity under "Technology."

The drivers of output and the output gap are different in each region. In the core, nondurable (consumption) preference shocks and aggregate demand (fiscal and external) shocks drive the behavior of output (38 and 24 percent). However, since technology shocks move potential output, they end up being an important driver of the output gap (50 percent), together with aggregate demand shocks (25 percent). Monetary shocks explain 9 percent of the fluctuations of both output and the gap, while the contribution of other shocks is small. In the HBS countries, financial, housing demand and technology are the main drivers of detrended output (29, 16, and 34 percent). However, once the effect of these shocks on potential is accounted for, the financial shocks are the one that explain output gap fluctuations in the HBS countries (65 percent).

The drivers of potential output, CPI inflation, house prices and credit are similar in both regions. As expected, technology shocks are the shocks that move potential output the most, explaining about 76 percent of its fluctuations at the core and 66 percent in the HBS countries. Interestingly, in the HBS countries, the effects of housing demand and risk shocks also affect potential: these shocks are fundamental and thus incorporated in the measure of potential. Markup and technology shocks roughly explain 30 percent of CPI inflation in each region. Monetary policy shocks have a stronger impact in the core (18 percent) while financial shocks have a stronger impact in the HBS countries (20 percent). In both regions, credit and house prices are mostly explained by housing preference shocks, specially in the HBS countries where they account for about 90 percent of the volatility of both variables. At the EMU level, both the output gap and CPI inflation are driven by a combination of several shocks.

\footnotetext{
${ }^{32}$ Posterior modes of the model parameters are numerically very close to the means we presented in Tables 2 and 3 . They are available upon request.
} 
Table 4: Variance Decomposition

\begin{tabular}{llllllll}
\hline \hline & Monetary & Financial & $\begin{array}{l}\text { Housing } \\
\text { Pref. }\end{array}$ & $\begin{array}{l}\text { Non-Durable } \\
\text { Pref. }\end{array}$ & Technology & $\begin{array}{l}\text { Aggregate } \\
\text { Demand }\end{array}$ & Markups \\
\hline Core & & & & & & & \\
\hline Output & 8.9 & 1.6 & 9.9 & 38.4 & 15.7 & 23.6 & 1.9 \\
Potential & 0.0 & 2.1 & 5.1 & 16.8 & 75.9 & 0.0 & 0.0 \\
Gap & 9.3 & 6.0 & 2.5 & 6.0 & 49.6 & 24.7 & 2.0 \\
Inflation & 17.8 & 8.4 & 2.1 & 8.0 & 30.5 & 0.1 & 33.1 \\
Credit Growth & 0.1 & 8.8 & 73.4 & 0.7 & 14.9 & 0.0 & 0.3 \\
House Prices & 1.7 & 0.6 & 82.4 & 0.7 & 14.0 & 0.0 & 0.7 \\
\hline & & & & & & & \\
HBS & & & & & & & \\
\hline Output & 5.6 & 29.1 & 15.7 & 6.4 & 34.3 & 7.2 & 1.8 \\
Potential & 0.0 & 9.4 & 19.1 & 4.8 & 66.8 & 0.0 & 0.0 \\
Gap & 7.0 & 64.7 & 2.8 & 1.6 & 12.7 & 9.0 & 2.3 \\
Inflation & 10.7 & 19.9 & 1.5 & 4.9 & 33.9 & 0.1 & 29.2 \\
Credit Growth & 1.8 & 6.1 & 90.8 & 0.1 & 2.9 & 0.0 & 0.1 \\
House Prices & 0.6 & 4.9 & 88.3 & 0.2 & 5.7 & 0.0 & 0.3 \\
\hline & & & & & & & \\
EMU & & & & & & & 0.0 \\
\hline Gap & 13.0 & 23.2 & 2.1 & 4.9 & 34.9 & 20.6 & 1.3 \\
Inflation & 18.2 & 13.3 & 1.9 & 7.8 & 35.1 & 0.1 & 23.7 \\
\hline \hline
\end{tabular}

Note: Variance decomposition computed at the posterior mode.

\section{Decomposing the Business Cycle in the Euro Area}

In this section, we use the estimated DSGE model to examine the business cycle in the euro area and to derive a measure of the output gap. To that end, we calibrate the parameters of the model at the posterior mode and extract the shocks using the observable variables and the Kalman smoother. ${ }^{33}$ We use the model to define the measure of potential output: the level of output consistent with flexible prices and wages, but with financial frictions, monopolistic competition and all other real frictions in place. This definition is now standard in the literature (see Galí, Smets and Wouters, 2011; Justiniano, Primiceri and Tambalotti, 2013), and it assumes that monetary policy can undo nominal rigidites, but not other sources of fluctuations. In addition, we remove price markup shocks from the definition of potential, but we keep all the other shocks in place. ${ }^{34}$

\footnotetext{
${ }^{33}$ See Harvey (1991).

${ }^{34}$ As discussed in the previous section, the aggregate demand shock basically acts as a measurement error shock between the model-based definition of GDP and the actual data. We describe in footnote 22 how we
} 
The definition of potential output also depends on the assumption about the existing predetermined (state) variables, such as the housing stock. As discussed in Adolfson et. al (2011), potential output can be either conditional or unconditional on the current state of the economy. Unconditional potential output is defined as the counterfactual level of output, had prices and wages always been exible. In contrast, conditional potential output is defined as the counterfactual level of output if prices and wages became exible only from the current period onward. The notion of potential output that we estimate in this section is the unconditional one. Hence, potential output depends on the counterfactual level of the housing stock that is independent from past policy.

Figures 2 and 3 present the shock decomposition of actual output, the output gap, credit growth and house prices in the core and HBS countries of the euro area. In order to facilitate the reading of the shock decomposition exercise, we aggregate the data to annual frequency, and we aggregate shocks across regions for each category, just the same way as in the variance decomposition exercise (Table 4). For instance, the "Markups" label aggregates price markup shocks in both regions of the euro area. The "Housing Preference" label aggregates the regionspecific and common housing preference shocks. We also consolidate the effects of all regionand sector-specific technology shocks, as well as the innovation to the permanent technology shock and the common component of the non-durable productivity under "Technology."

We find that the cycle was very different in the both regions. In the HBS countries, easy monetary policy and financial conditions (reflected in lower country risk premia) between 20002005 led to a take-off of housing prices, credit and GDP in some countries and hence, in the aggregate. By mid-2000s, it was housing demand shocks that lead to a large boom-and-bust cycle in house prices, credit and GDP, in a process that was reinforcing before and after the crisis hit. In the core, these phenomena were absent, and all variables display much smaller fluctuations, which were not generally driven by housing demand shocks. Aggregate demand shocks played a stronger role. In general, monetary policy shocks had a countercyclical effect, but more so in the core than in the HBS countries.

\section{A. HBS Countries}

The HBS countries of the euro area as a whole went through a large, credit and housing fuelled boom and bust cycle during the sample period. ${ }^{35}$ In Figure 3 (right panel), output starts growing above trend since 2002, with the contribution of housing demand and financial shocks being very prominent. Housing demand shocks represent between a third and a half of the contribution to the boom cycle between 2002-2008, which is remarkable given that the size of

attribute the fraction that corresponds to business investment to labor productivity, through capital deepening.

${ }^{35}$ Italy was an exception with milder credit growth, real house price appreciation and real GDP growth than the other countries in the same group.

CInternational Monetary Fund. Not for Redistribution 
the housing sector is 6 percent of GDP. ${ }^{36}$ As we discussed in the model section, housing demand shocks are a proxy for unmodeled factors such as population growth or speculative behavior in the housing market. They can also proxy for deviations from rational expectations, as in the learning literature such as Adam, Kuang, and Marcet (2011). The collapse of output in 2012-2013 is mostly attributed to financial shocks, reflecting the tensions in the intra-european financial markets and the sudden stop suffered by the HBS countries.

Next, we discuss the behavior of the output gap, where we have substracted potential output, using the standard definition outlined at the beginning of this section. The behavior of the output gap has important qualitative and quantitative differences, because movements in the output gap reflect differences in the impact that other shocks have on the behavior of both actual and potential output. For example, during the boom years (mid 2000s), the output gap is mainly driven by financial shocks (both regon-wide and housing risk). ${ }^{37}$ Housing demand shocks also affect potential to the extent that these shocks represent fundamental changes in the potential amount of the housing stock (think of increased demand due to immigration). Hence, their contribution to output gap volatility is lower than that of detrended output.

The output gap deteriorated in the last two years and was about -4 percent of GDP at the end of 2013. Monetary policy had a countercyclical effect for most of the sample period, but it was not enough to offset fluctuations and adverse shocks. During the crisis, monetary policy provided much needed support to the HBS countries, but it was not able to counteract the strong headwinds faced by these economies, which included banking sector impaired balance sheets, strong private sector deleveraging, weak confidence, and a tight fiscal stance. The zero lower bound on nominal interest rates also constrained the ability to conduct more expansionary monetary policy.

Figure 4 (right panel) provides clear evidence that credit developments were driven by the housing boom in the aggregate of HBS countries. Virtually all of credit (in deviations from trend) is driven by the housing preference shock. In the initial phase of the credit boom, financial shocks contributed to the increase in credit (2001-2004). Later the boom took a life of its own reflecting mostly housing demand shocks, which also pushed up house prices and set off a strong feedback loop. that turned in reverse after 2009. Financial shocks also contributed to the decline in credit. Monetary policy appears to have had a small effect on credit.

\footnotetext{
${ }^{36}$ The calibration represents the long-run average size of residential investment in GDP. This ratio peaked at about 9 percent of GDP in Spain in 2007. See Aspachs-Bracons and Rabanal (2010).

${ }^{37}$ See Neumeyer and Perri (2005) for an RBC model where spread shocks between domestic and world interest rates are a main driver of fluctuations.
} 
Figure 3: Shock Decomposition, Output and Output Gaps

Core Output

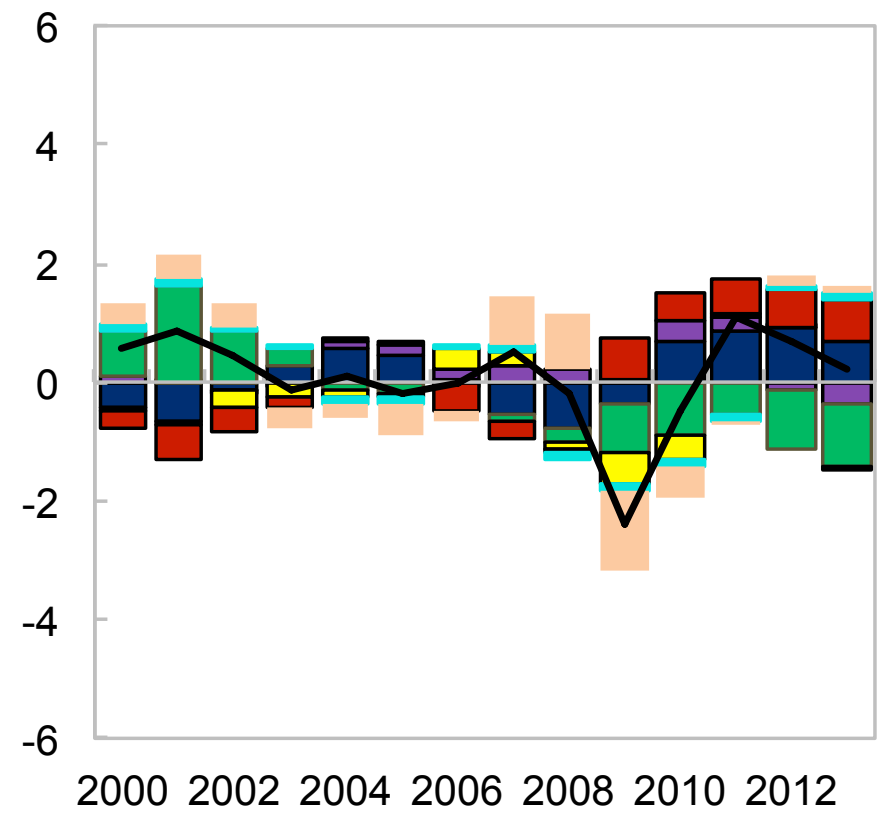

HBS Output

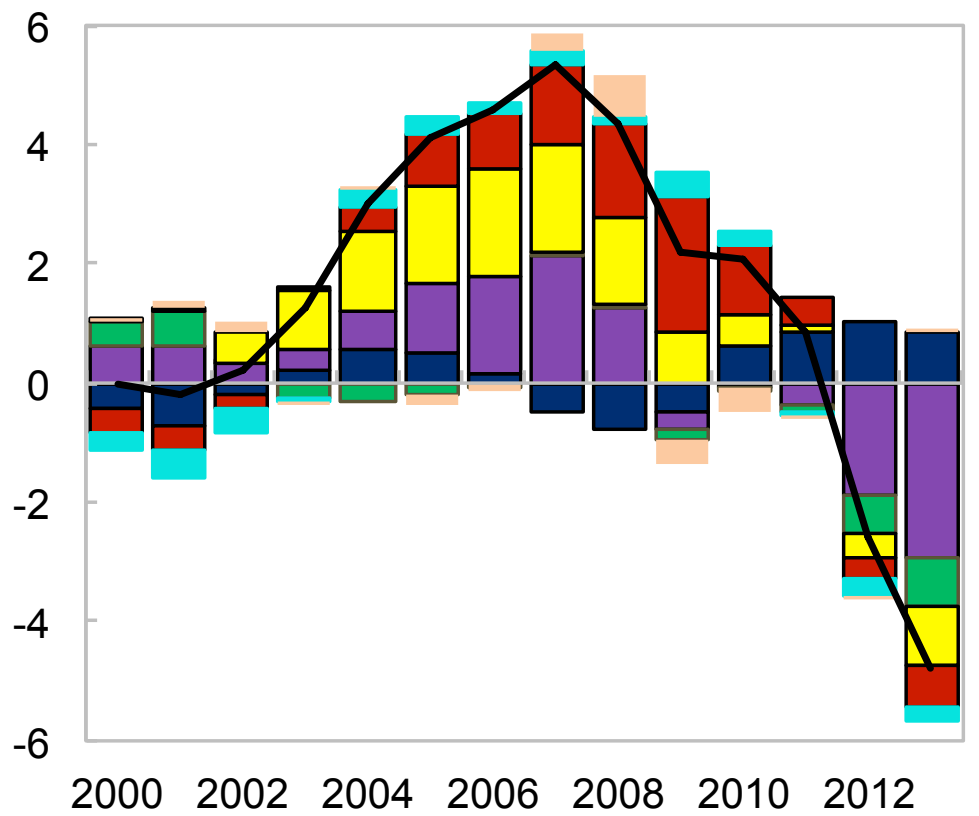

\section{Core Output Gap}

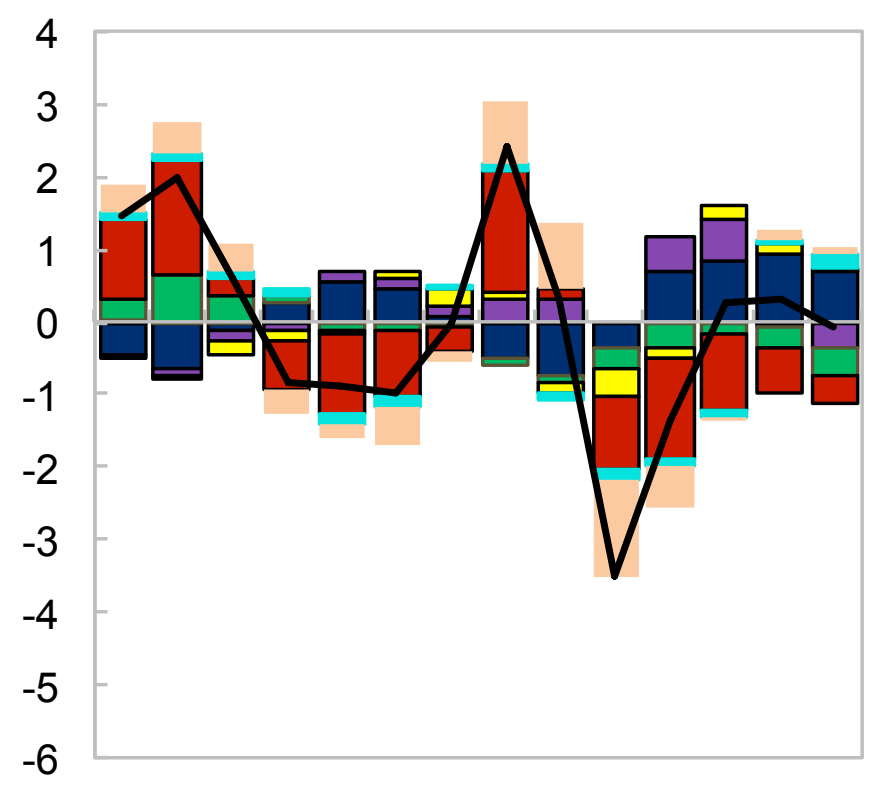

2000200220042006200820102012
HBS Output Gap

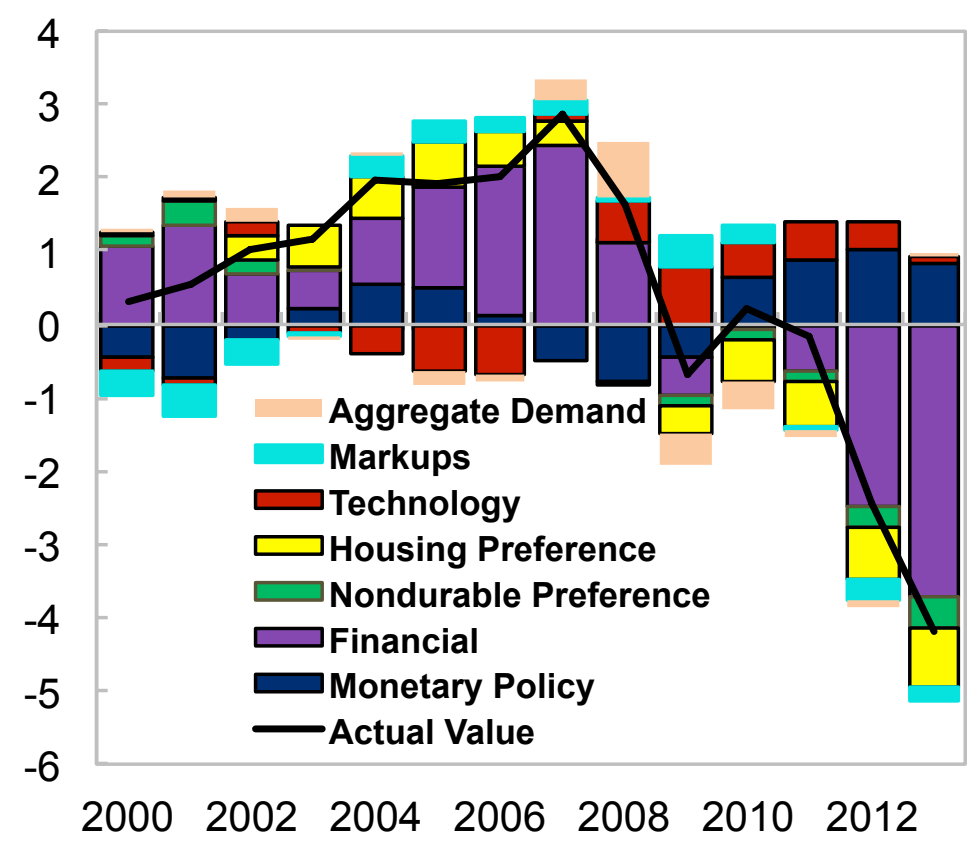

Note: Horizontal axis shows the year and vertical axis presents percentage deviation of the variables from its trend (Output) and from potential output (Output Gap). 
Figure 4: Shock Decomposition, Credit and House Prices

Core Credit

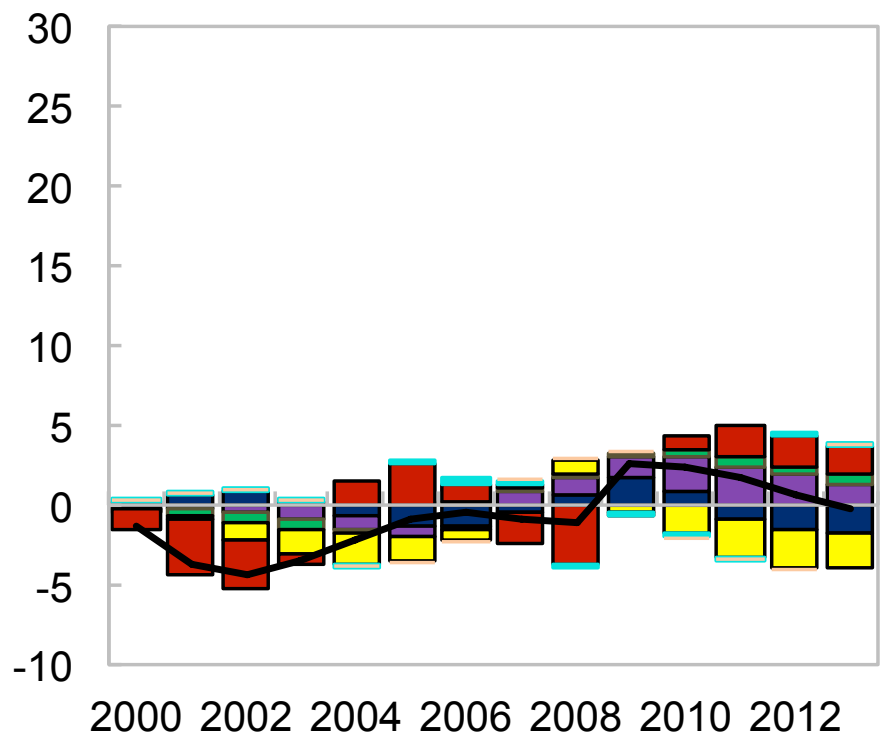

Core House Prices

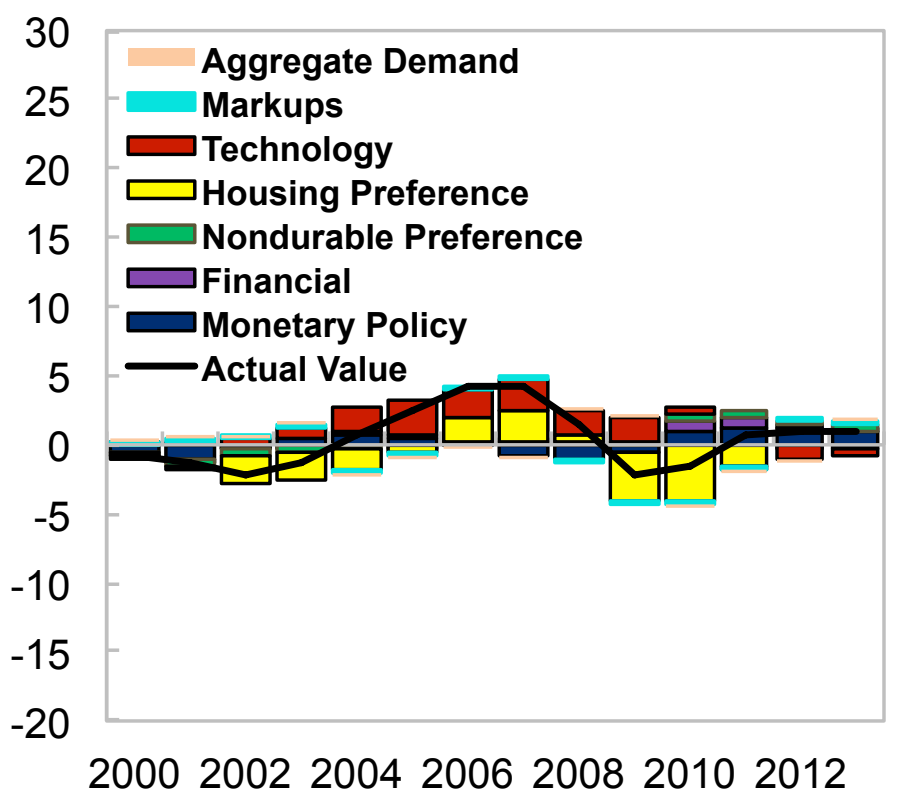

HBS Credit

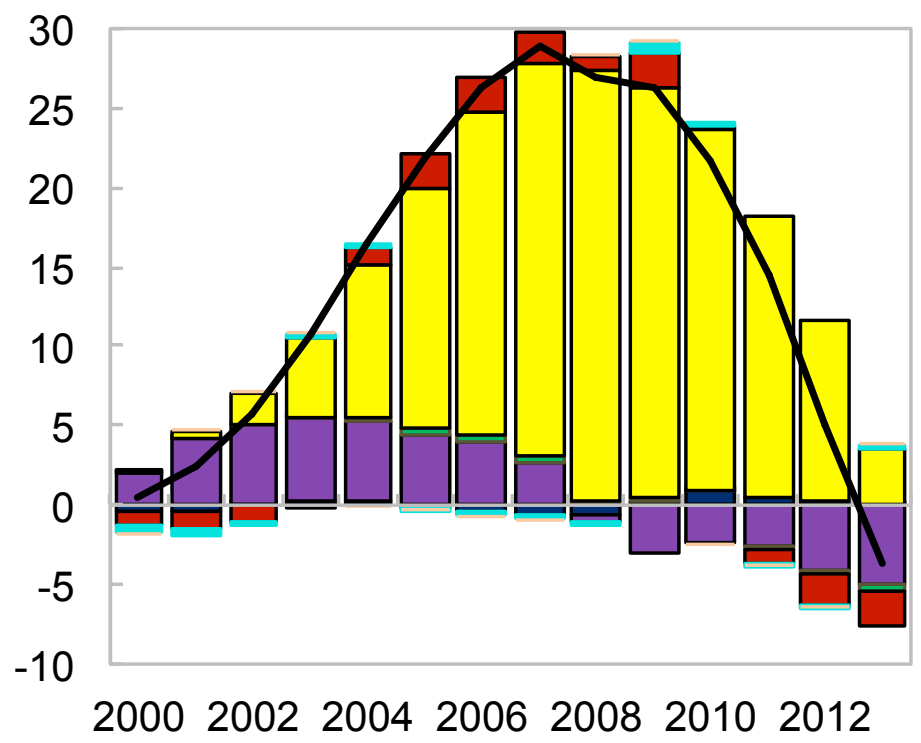

HBS House Prices

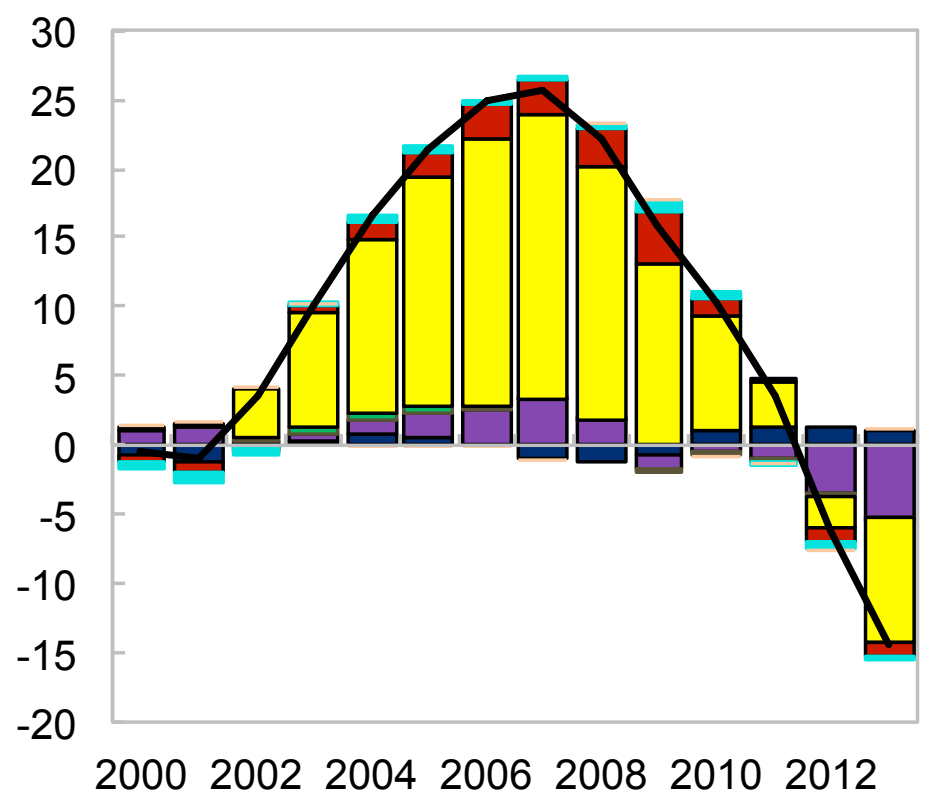

Note: Horizontal axis shows the time and vertical axis presents percentage deviation of the variables from their trend. 


\section{B. Core}

The experience of the core was very different from the HBS countries. Actual output was close to trend for most of the first half of the decade, and housing demand shocks did not play a role in explaining fluctuations (Figure 3, left panel). They contributed negatively during 2009-2010, but the main driver of the fluctuations in the core are aggregate demand (i.e. external and fiscal) shocks, and preference shocks to non-durable consumption. In fact, aggregate demand shocks had an important impact in the aftermath of the GFC. In general, monetary policy played a countercyclical role for the core. The output gap is somewhat more volatile than detrended output. After the introduction of the euro, the core experienced a mild expansion, which turned into a negative output gap for most of the 2000s. The core output gap turned positive again in 2007-2008, collapsed during the GFC, but rebounded afterwards, driven by aggregate demand shocks and to a lesser extent, productivity and non-durable consumption shocks. According to the model, the output gap was close to zero at the end of 2013. Monetary policy had a stabilizing role for the core in the whole sample.

Figure 4 (left panel) shows that credit in the core was subdued for most of the sample, and that there was no credit boom and bust cycle. Because housing demand was not a main driver, a combination of other shocks had some influence. House prices where also much less volatile in the core, driven by a combination of housing preference, productivity and monetary policy shocks. While there was only a moderate boom in the mid-2000, the model identifies two small busts at the beginning and the end of the 2000s, driven by low housing demand.

\section{The Role of Financial Frictions}

After having provided a decomposition of the recent boom and bust cycle in the euro area through the lens of a DSGE model, in this subsection we examine what is the role of financial frictions in explaining and amplifying macroeconomic fluctuations. One way to illustrate the relevance of these frictions is to compare the output gap coming from the estimated model, with an alternative definition of the output gap where in addition to nominal frictions and mark-up shocks, financial frictions and risk shocks are also removed (by setting $\lambda=1$ ). ${ }^{38}$ Also, we find it useful to compare the DSGE model and the HP-filter implied output gaps.

\footnotetext{
${ }^{38}$ We do not reestimate this version of the model without financial frictions but keeping all other nominal and real rigidities in this exercise. We want to feed the exact same shocks to the two definitions of potential output and output gap, where the only difference in the transmission mechanism is the financial friction, and where all other parameters are the same. Hence, the output gap implied by the "No Financial Frictions" model is the counterfactual level of the output gap, had the history of the shocks and the value of the parameters been the same as the model with financial frictions, while the financial accelerator mechanism is turned off.
} 
Figure 5: Output Gaps and Financial Wedges

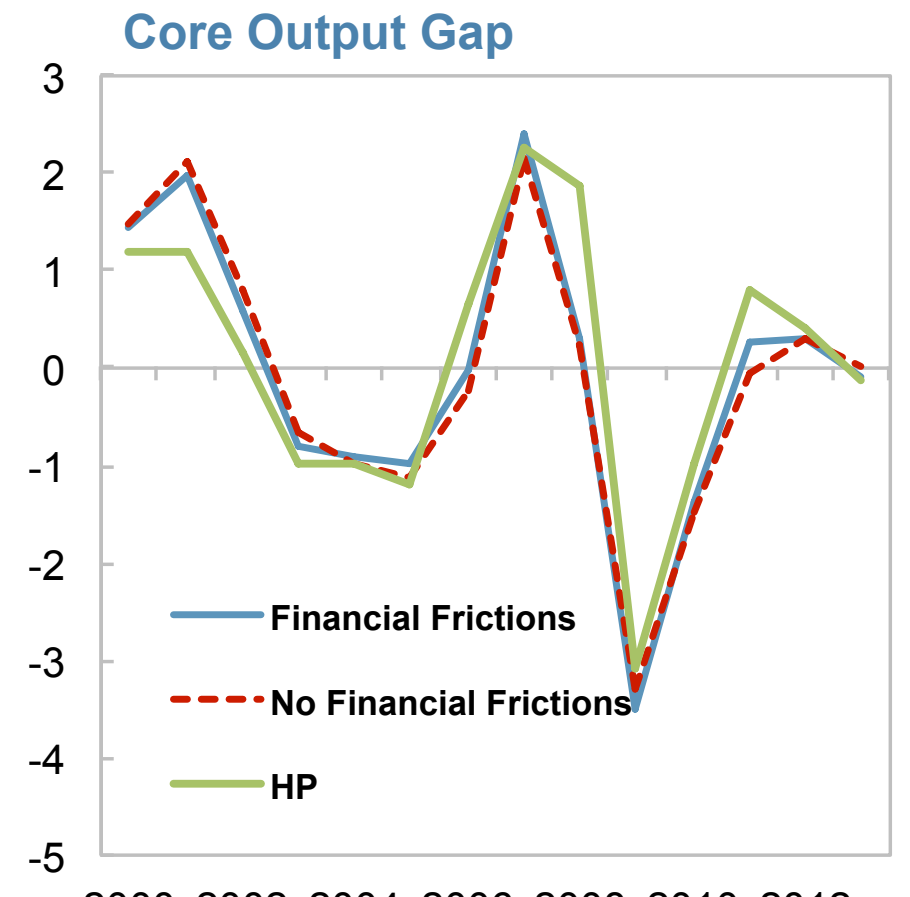

2000200220042006200820102012

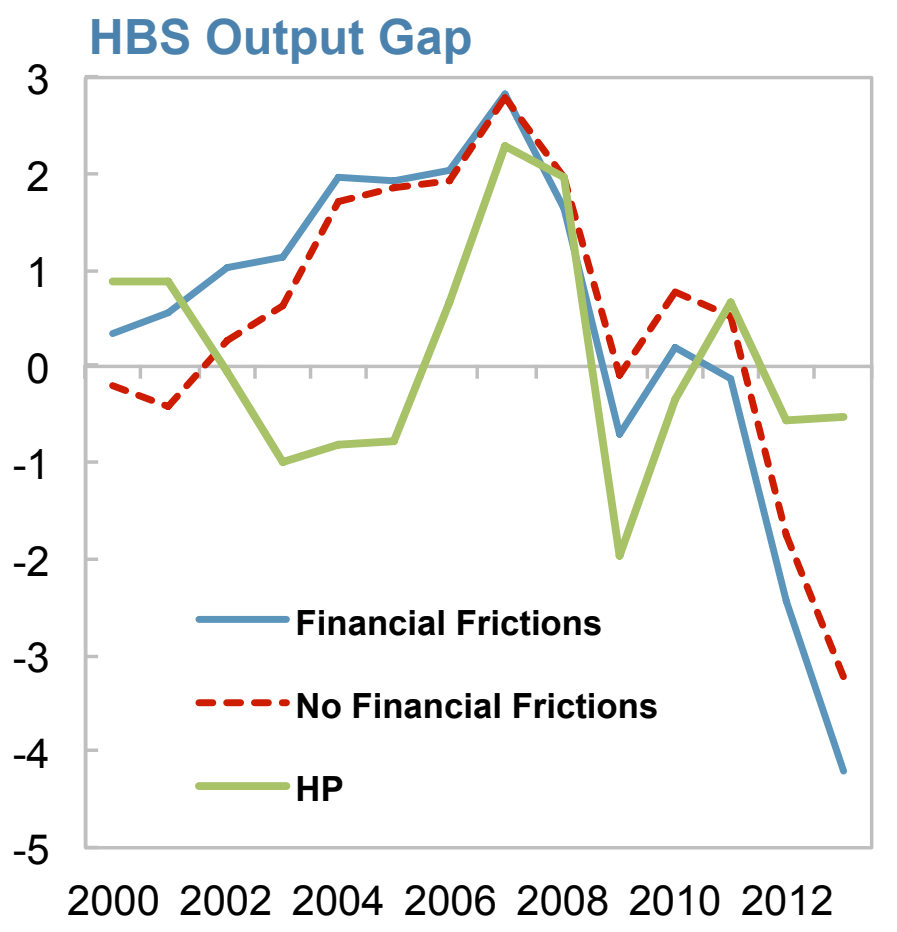

Financial Wedge HBS

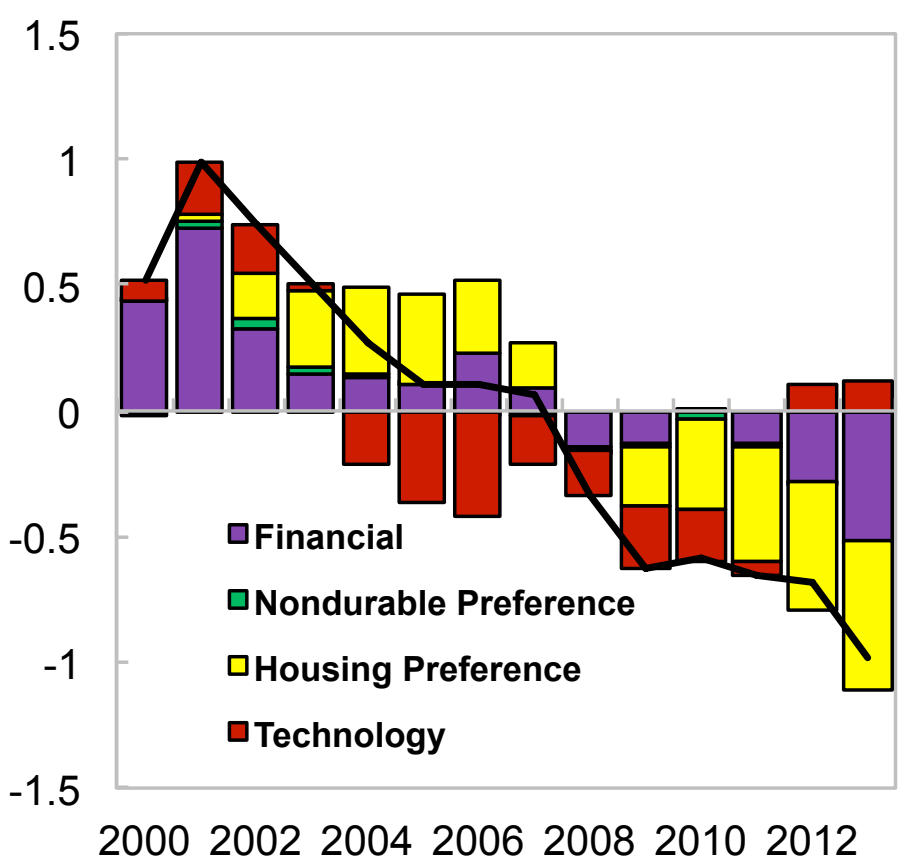

Note: Horizontal axis shows the year and vertical axis presents percentage deviation of the variables from their steady state. 
The results are quite different for both regions (Figure 5). In the core, the two gap measures are very similar, denoting that financial frictions and shocks did not matter so much because of the lack of a housing and credit boom. In addition, the measure coming from the HP filter is also quite similar. This coincidence is remarkable, given the differences in the underlying methodologies. In contrast, the output gap in the model with financial frictions is more volatile than its counterpart without financial frictions in the HBS countries. Financial frictions mattered much more precisely because financial and housing demand shocks are the ones that set the financial accelerator in motion, and those shocks were more important in the HBS countries. Hence, for this group of countries, we obtain a result similar to Furlanetto, Gelain, and Taheri Sanjani (2014): the measure of output gap is affected by the introduction of financial frictions. Finally, it is worth noting that the DSGE model and the HP filter give radically different answers, which imply different policy responses. The HP filter delivers a negative output gap for most of the mid-2000s. Also, while it seems to capture the final part of the boom in 2007 and the subsequent bust in 2008-2009, it implies a close-to-zero gap by 2013, which is at odds with other evidence that was not used to estimate the model (such as high unemployment rates) in the HBS countries.

Another way to understand the role of financial frictions is to decompose the difference between the gaps implied by both models (with and without financial frictions). As expected, the main difference is in the different response to financial and housing demand shocks. To do this exercise, we define the "financial wedge," which is the difference between output gaps in a model with and without financial frictions:

$$
\begin{aligned}
F W_{t} & =g a p_{t}^{F F}-g a p_{t}^{N O F F} \\
& =\left(y_{t}-\tilde{y}_{t}^{F F}\right)-\left(y_{t}-\tilde{y}_{t}^{N O F F}\right)= \\
& =\tilde{y}_{t}^{N O F F}-\tilde{y}_{t}^{F F} .
\end{aligned}
$$

where $\tilde{y}$ is potential output and the superscript denotes if it includes financial frictions or it does not.

Because actual output $\left(y_{t}\right)$ is not model dependent, the financial wedge is thus defined as the difference between the potential output derived from a counterfactual baseline model without financial frictions to the one including financial frictions. After joining the euro (20002002), financial shocks explain the larger gap during the boom part of the cycle, but starting in 2003 the housing preference shock takes over as the main shock amplified by the financial friction. In fact, the housing boom is offsetting the negative contribution of financial shocks and productivity. When the crisis hits, the negative housing demand shocks are amplified through the accelerator mechanism, explaining the more negative gap. In contrast, the financial wedge estimated for the core shows much less dramatic movement, and while it is also driven by 
housing demand shocks, their contribution is relatively much smaller. ${ }^{39}$

\section{Does One Monetary Policy Fit All?}

In the previous section, we have shown that output gaps in both regions have been affected by different shocks, and that both measures are not necessarily synchronized. We have also seen that monetary policy shocks have played a countercyclical role in the core, while they amplified fluctuations in the HBS countries at times, specially during the mid-2000s. This rises the question of how appropriate the common monetary policy stance of the euro area has been for both regions. ${ }^{40}$

In the top panel of Figure 6 we present the evolution of the natural real interest rate (NRIR) for the core and the HBS countries. The natural rate is defined the same way as potential output: the level of real interest rates consistent with flexible prices and wages, and where inefficient (price mark-up) shocks are excluded. The determinants and the evolution of both real interest rates were quite different, which means that one monetary policy might not be appropriate for both regions at the same time. In the core, the real rate has been declining overtime, and it has been below its historical mean since the global financial crisis. Interestingly, the core natural real rate tracks the output gap, it initially declined during 2000-2006 and then jumped in 2007. The fluctuation in the HBS countries' NRIR was small but positive during the over heating period 2000-2007, when the output gap was also positive. The tension between the core and the HBS countries became evident during the 2003-2006 period, when the core needed lower rates and the HBS group higher rates. However, the synchronization of the last part of the boom, and then the bust, makes the natural rates converge again, at least in sign.

To understand the degree of appropiateness of monetary policy in each region, we compute the following series:

$$
D e v_{t}^{i}=r_{t}-r_{t}^{T, i}, \quad i=[\operatorname{core}, H B S]
$$

where $r_{t}$ is the three month Euribor rate, and $r_{t}^{T, i}$ is the prescription of the Taylor rule (equation 25) using the estimated parameters of Table 2, but using region-specific CPI inflation and output growth rates. ${ }^{41}$ Figure 6 , bottom panel, presents the results. A positive deviation implies that

\footnotetext{
${ }^{39}$ The financial wedge is the difference of potential output for the two models. Since price mark-up shocks are excluded from the definition of potential output, they do not appear in the shock decomposition. The aggregate demand shock has the exact same impact on both measures of potential output, and disappears from the wedge.

${ }^{40}$ In this subsection, we focus on monetary policy only. A more comprehensive approach would include the appropiateness and effectiveness of the aggregate macroeconomic policy mix, incuding macroprudential and fiscal policies in each region.

${ }^{41}$ Quint (2014) studies a similar measure of monetary policy stress for all member countries of the euro area, and also derives an average measure for the monetary union. It concludes that the degree of monetary policy stress in the euro area is similar to that in the United States and in pre-euro Germany.
} 
the stance of monetary policy is contractionary.

Figure 6: Natural Rates of Interest and Deviations from Taylor Rule
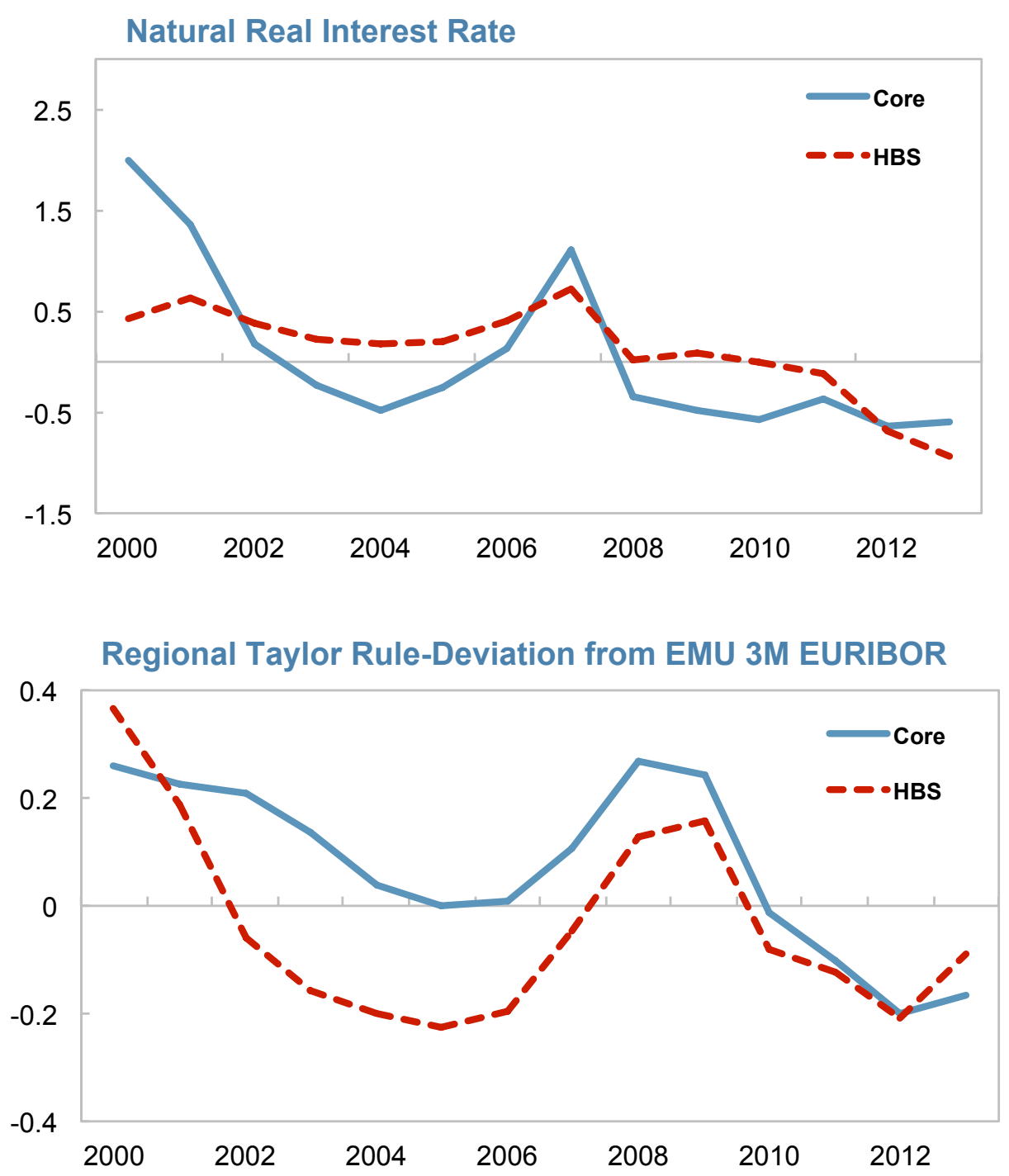

Note: Horizontal axis shows the time and vertical axis presents percentage deviation of the variables from their steady state.

In the core, monetary policy was contractionary in the 2000-2003 period, and then it was about right between 2004-2006. After the pick-up in inflation in 2007-2008 and the associated tightening by the ECB, policy become too contractionary in 2008-2009, and then expansionary when the crisis hit from 2010 onwards. In contrast, the stance of monetary policy was initially contractionary for the HBS countries, but it became largely expansionary between 2002-2006. It was precisely in this period that monetary policy behaved in a pro-cyclical way for the 
HBS countries, contributing somewhat to the overheating of the economy. Policy became contractionary towards the end of the boom (due to the increase of inflation around 20072008), and expansionary when the crisis hit. Therefore, the ECB faced an important trade-off until 2007, because it was not possible to calibrate interest rates to satisfy both regions of the euro area. After the crisis, the synchronization of the recession made it easier for the ECB to provide a "one size fits all" monetary policy. But as we saw in Figures 2 and 3, while monetary policy provided much needed stimulus, it was not enough to close the output gap in the HBS countries.

\section{Impulse Response Analysis}

In this section, we comment on the estimated impulse response functions (IRFs) to understand the effects of the main shocks. Given the results of the shock decompositions of the previous section, we focus on the effects of financial (HBS risk premium and housing risk) shocks, housing demand shocks and the monetary policy shock (Figures 7-9). In each case, the shock is one standard deviation but the sign is chosen to produce a contraction. Impulse response functions are computed at the estimated posterior modes.

Figure 7 shows the impulse response functions to three different financial shocks. All financial shocks create a contraction with three common features: first, real quantities and prices decline due to the financial accelerator channel. Second, while the impact response is quantitatively larger in the HBS countries, the spillover effect is more pronounced in the core, which further highlights the trade links between the two regions. Finally, the size of the response of house prices is larger than the responses of nondurable goods (CPI) inflation, thereby triggering a relatively small response by the ECB.

In the core, a housing sector risk shock leads to an output decline of about 0.06 percent below its steady state, and a further decrease within the following two quarters. CPI Inflation initially falls about 0.025 percent and returns slowly to its steady-state value. There are spillover effects to the HBS countries but they are quantitatively small. In the HBS countries, the magnitude of the responses is much larger under a housing risk shock. The region specific housing sector shock creates a larger contraction, of almost 0.2 percent, with also larger declines in house prices and CPI inflation. Through the trade channel, output and CPI inflation also fall in the HBS countries, and the EMU gap also declines. However, because of the different economic sizes, the EMU CPI inflation declines by less when the shock hits the HBS countries, and the response of the ECB is therefore more muted.

The risk premium shock, by directly affecting deposit and lending rates in the HBS countries, has the biggest macroeconomic impact of all financial shocks. The contraction in output, CPI

CInternational Monetary Fund. Not for Redistribution 
Figure 7: IRF - Financial Shocks

Core Output
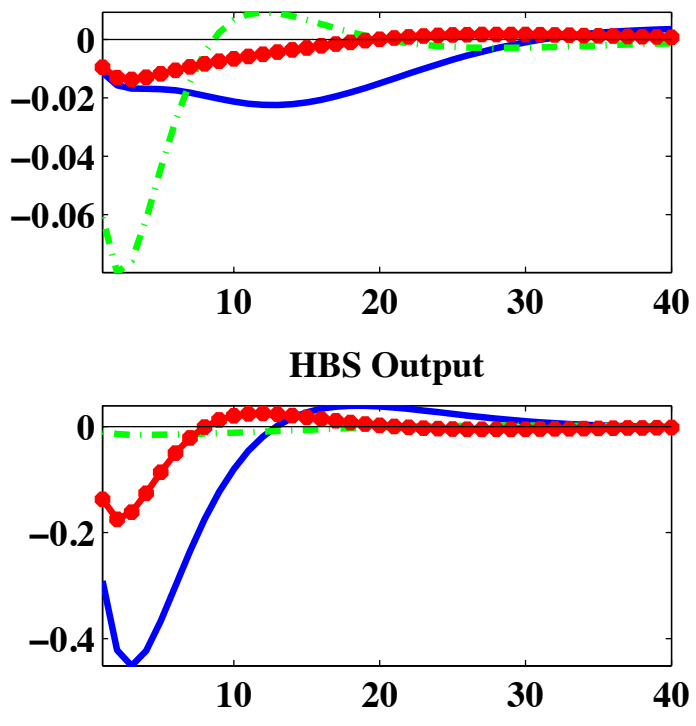

EMU Output

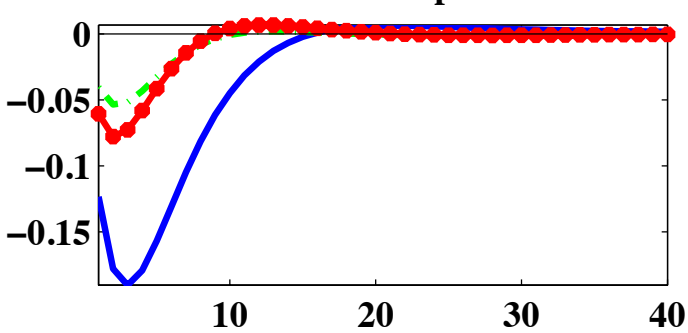

Core CPI Inflation
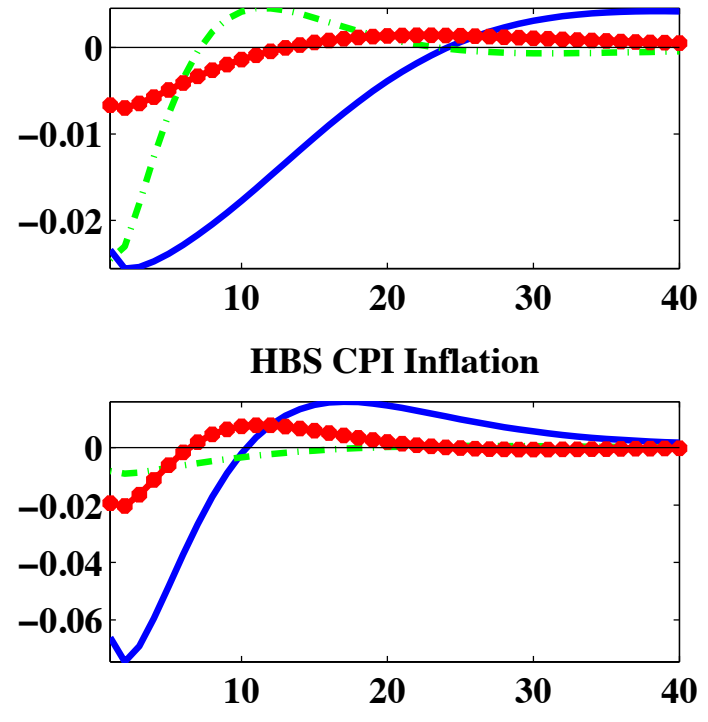

EMU CPI Inflation

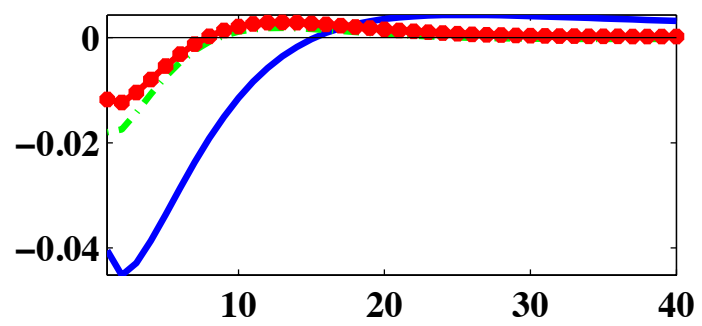

Core House Prices

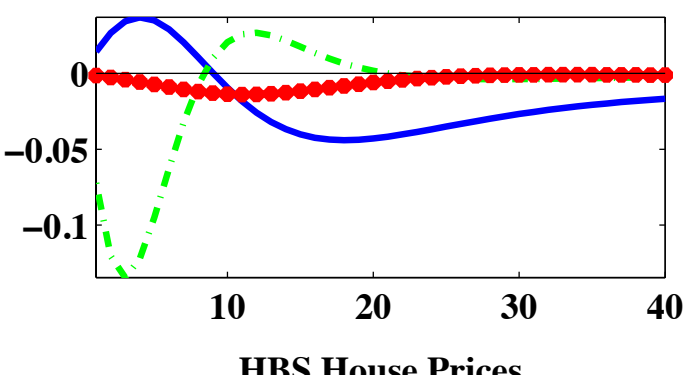

HBS House Prices

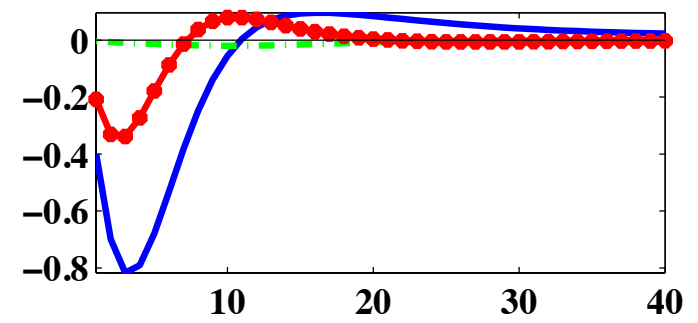

EMU 3m EURIBOR

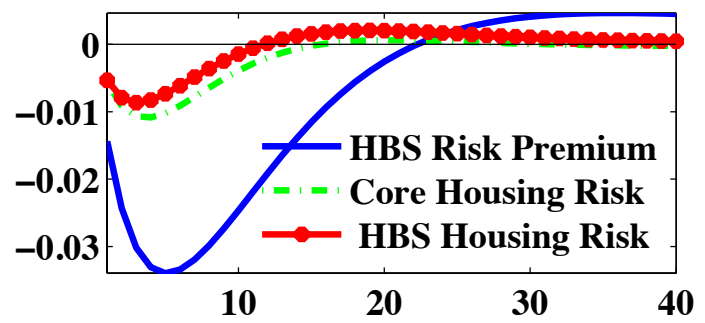

Note: Horizontal axis shows quarters after the shock and vertical axis presents percentage deviation of the variables from their steady state. 
Figure 8: IRF -Housing Demand Shocks

Core Output
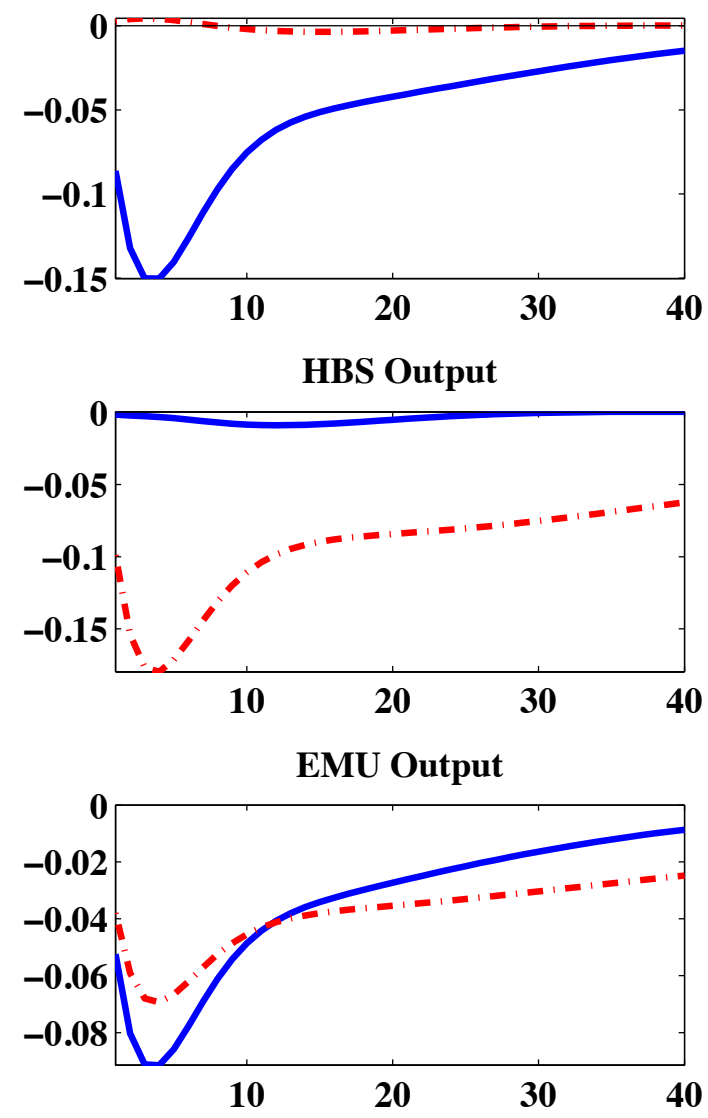

Core CPI Inflation
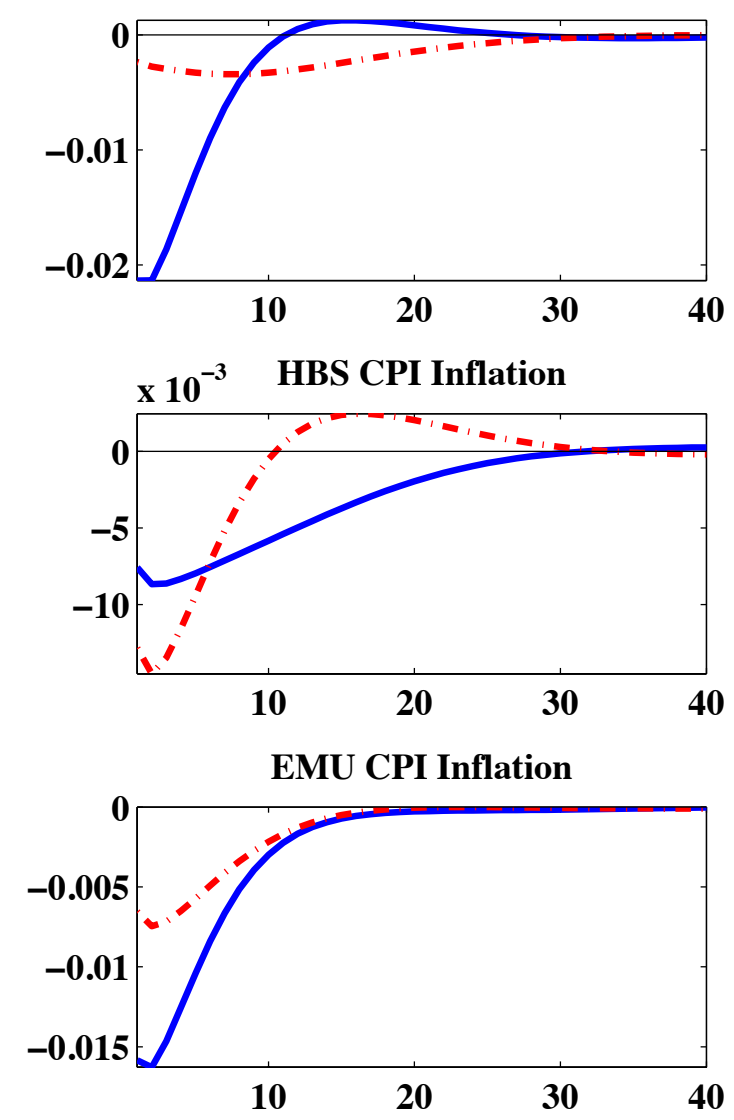

Core House Prices
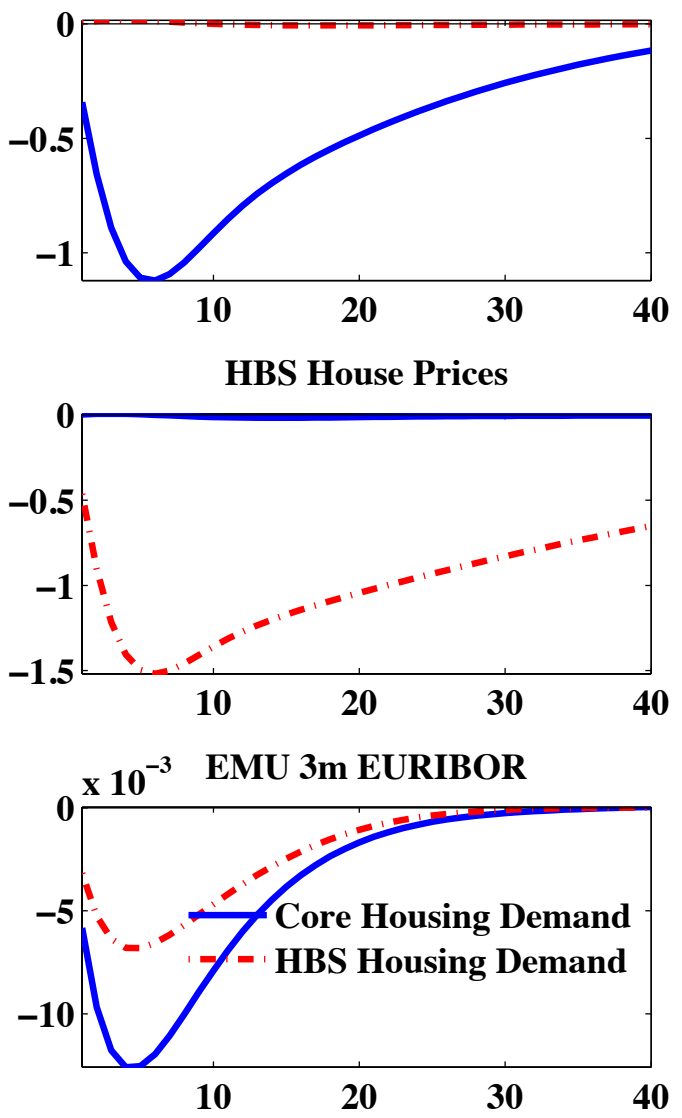

Note: Horizontal axis shows quarters after the shock and vertical axis presents percentage deviation of the variables from their steady state. 
Figure 9: IRF -Monetary Policy Shocks
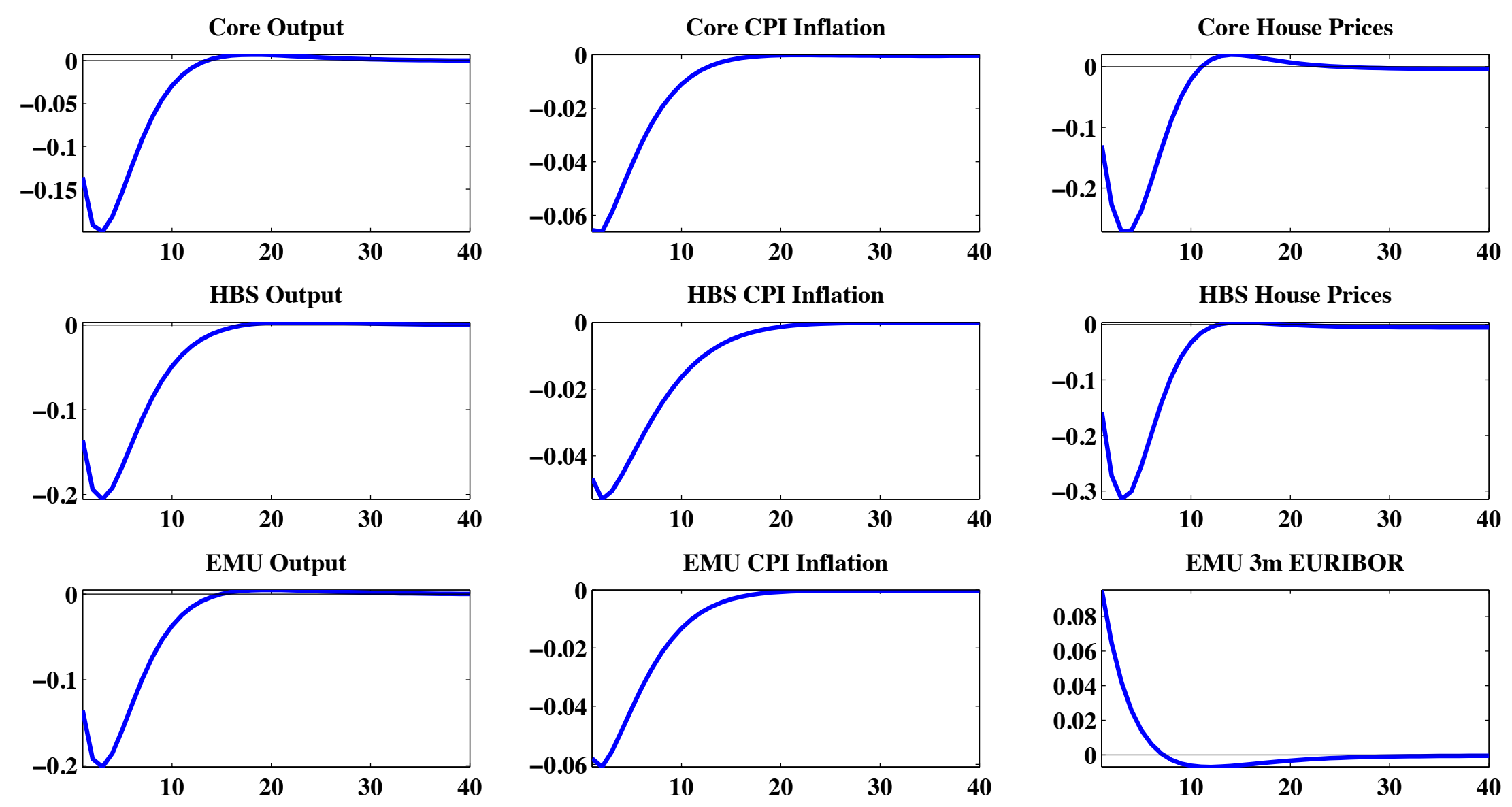

Note: Horizontal axis shows quarters after the shock and vertical axis presents percentage deviation of the variables from their steady state. 
inflation and house prices is close to three times larger because this shock affects not only the housing market risk and the lending rate but the whole economy. With house prices falling sharply, borrowers balance sheets deteriorate, accelerating the initial drop, because lendingdeposit spreads increase. Through the trade channel, core output and CPI inflation decline, and while nominal house prices decline, real prices increase. Since the risk premium shock has the largest effect on both regions, the ECB acts more forcefully cutting rates.

Figure 8 shows the impulse response functions to the region-specific housing demand shocks. In both cases, the effects are similar: a decline of domestic residential investment and house prices, which then gets transmitted to the nondurable sector because of balance sheet effects, thereby leading to a decline in CPI inflation. The recessionary impact of the shock is therefore long lasting. In both cases, the ECB cuts rates after the housing bust, which leads to different spillovers: HBS countries output declines after a housing bust in the core because the trade channel outweights the cut in interest rates. In the core spillovers are indeed positive: output increases because the effect of monetary policy is larger than the trade effect.

Finally, in Figure 9 we show the effects of a monetary policy shock. The transmission mechanism of monetary policy is qualitatively similar, reflecting similar estimated parameters in both regions. The real effects are similar, both in terms of impact and hump-shaped response in both regions. The effects on prices are somewhat more different. The response of house prices to a monetary policy tightening are larger in the HBS countries, while the response of CPI inflation is somewhat larger in the core.

\section{Conclusions}

In this paper, we have presented a DSGE-model based approach to decompose the business cycle and compute potential output and output gaps in the euro area, taking into account financial variables, frictions, and shocks. The model includes housing and a financial accelerator mechanism on the household side, such that changes in house prices affect balance sheets, access to credit and default rates by borrowers who use their house as collateral, thereby affecting aggregate demand. We have shown that the introduction of financial variables (both in the model and in the estimation) matter specially for countries that have experienced large fluctuations in housing and credit variables, like the aggregate of HBS countries of the euro area during the 2000s. Moreover, we have shown that the use of the HP filter gives the wrong picture regarding the cyclical position of the countries that faced credit and housing price fluctuations. However, in the euro area core, where there was no credit boom, including financial variables does not seem to matter and does not change the assessment that comes from the HP filter. We have also shown that the output gaps coming from the DSGE model at the end of the sample correlate better with other available evidence (such as high unemployment rates) than the HP 
filter: in particular, we estimated a negative output gap of 4 percent of GDP by end-2013, while the HP filter suggests a much smaller gap.

As is well known in the literature, different modelling choices can lead to different estimates of the output gap, as shown by Galí, Smets and Wouters (2012), and Furlanetto, Gelain and Taheri Sanjani (2014). Because the output gap is not observable, we cannot provide an ex-post evaluation of which approach is the best one. We would like to highlight that our modeling choices have been made based on the standard New Keynesian modeling literature, adjusted to include household credit and housing. We have also addressed potential mispecification as we have more shocks in the model than the number of endogenous series employed in the estimation, as suggested by Smets and Wouters (2003). This allows us to understand which shocks are important and which shocks are not, after we have estimated the model. But we acknowledge that more work is needed to take into account model uncertainty. 


\section{References}

[1] Adam, K., Kuang, P., and A. Marcet, 2011. House Price Booms and the Current Account. NBER Macroeconomics Annual, Vol. 26, pp. 77-122.

[2] Adolfson, M., Laseen, S., Lindé, J., and L. Svensson, 2011. Optimal Monetary Policy in an Operational Medium-Sized DSGE Model. Journal of Money, Credit, and Banking, Vol. 43(7), pp. 1287-1331.

[3] Adolfson, M., Laseen, S., Lindé, J., and M. Villani, 2007. Bayesian Estimation of an Open Economy DSGE Model with Incomplete Pass-Through. Journal of International Economics, Vol. 72(2), pp. 481-511.

[4] An, S. and F. Schorfheide, 2007. Bayesian Analysis of DSGE Models. Econometric Reviews, Vol. 26(2-4), pp. 113-172.

[5] Aspachs-Bracons, O. and P. Rabanal, 2010. The drivers of housing cycles in Spain. SERIEs, Spanish Economic Association, Vol. 1, No. 1, pp. 101-130.

[6] Benes, J., K. Clinton, R. Garcia-Saltos, M. Johnson, D. Laxton, P. Manchev and T. Matheson, 2010. Estimating Potential Output with a Multivariate Filter. IMF Working Paper 10/285.

[7] Berger, H., Dowling, T., Lanau, S., Lian, W., Mrkaic, M., P. Rabanal, and TaheriSanjani, M., 2015. Steady As She Goes-Estimating Potential During Financial "Booms and Busts", IMF, mimeo.

[8] Bernanke, B., Gertler, M., and S. Gilchrist, 1999. The Financial Accelerator in a Quantitative Business Cycle Framework. In: Taylor, J., Woodford, M. (Eds.), Handbook of Macroeconomics, Vol. 1, pp. 1341-1393.

[9] Borio, C., Disyatat, P., and M. Juselius, 2014. A parsimonious approach to incorporating economic information in measures of potential output, BIS Working Papers 442.

[10] Calvo, G., 1983. Staggered Prices in a Utility Maximizing Framework. Journal of Monetary Economics, Vol. 12(3), pp. 383-398.

[11] Christiano, L., Eichenbaum, M., and C. Evans, 2005. Nominal Rigidities and the Dynamic Effects of a Shock to Monetary Policy. Journal of Political Economy, Vol. 113(1), pp. 1-45.

[12] Christiano, L., Ilut, C., Motto, R., and M. Rostagno, 2008. Monetary Policy and Stock Market Boom-Bust Cycles. ECB Working Paper No. 955, October.

[13] Christiano, L., Motto, R., and M. Rostagno, 2014. Risk Shocks. American Economic Review, Vol. 104, No. 1, pp. 27-65. 
[14] Claessens, S., Kose, A., and M. E. Terrones, 2009. What Happens During Recessions, Crunches and Busts? Economic Policy, Vol. 24, pp. 653-700.

[15] Clarida, R., Galí, J., and M Gertler, 1999. The Science of Monetary Policy: A New Keynesian Perspective. Journal of Economic Literature, Vol. 37, No. 4, pp. 1661-1707.

[16] Cúrdia, V., and M. Woodford, 2009. Credit Frictions and Optimal Monetary Policy. BIS Working Papers No. 278.

[17] European Central Bank, 2009. Housing Finance in the Euro Area. ECB Occasional Paper No. 101.

[18] Fabiani, S., M. Druant, I. Hernando, C. Kwapil, B. Landau, C. Loupias, F. Martins, T. Mathä, R. Sabbatini, H. Stahl, and A. Stokman, 2006. What Firms' Surveys Tell Us About Price-Setting Behavior in the Euro Area. International Journal of Central Banking, Vol. 2, No. 3, pp. 3-47.

[19] Furlanetto, F., Gelain, P., and M. Taheri Sanjani, 2014. Output Gap in the Presence of Financial Frictions and Monetary Policy Trade-Offs, IMF Working Paper 14/128.

[20] Forlati, C., and L. Lambertini, 2011. Risky Mortgages in a DSGE Model. International Journal of Central Banking, Vol. 7, No. 1, pp. 285-336.

[21] Galí, J., Smets, F., and R. Wouters, 2012. Unemployment in an Estimated Ney Keynesian Model, NBER WP 17084.

[22] Gerali, A., Neri, S., Sessa, L., and F. Signoretti, 2010. Credit and Banking in a DSGE Model of the Euro Area. Journal of Money, Credit and Banking, Vol. 42(s1), pp. 107-141.

[23] Harvey, A., 1991. Time Series Models. MIT Press.

[24] Hodrick, R. and E.C. Prescott, 1997. Postwar U.S. Business Cycles: An Empirical Investigation. Journal of Money, Credit and Banking, Vol. 29, No. 1, pp. 1-16.

[25] Iacoviello, M., 2005. House Prices, Borrowing Constraints and Monetary Policy in the Business Cycle. American Economic Review, Vol. 95(3), pp. 739-764.

[26] Iacoviello M., and S. Neri, 2010. The Role of Housing Collateral in an Estimated TwoSector Model of the U.S. Economy. American Economic Journal: Macroeconomics, Vol. 2, No. 2, pp. 125-164.

[27] International Monetary Fund, 2012. Dealing with Household Debt. Chapter 3 of World Economic Outlook, April 2012, International Monetary Fund, Washington, DC.

[28] International Monetary Fund, 2013. The Dog that Didn't Bark: Has Inflation Been Muzzled or Was It Just Sleeping? Chapter 3 of World Economic Outlook, April 2013, International Monetary Fund, Washington, DC. 
[29] Justiniano, A., Primiceri, G., and A. Tambalotti, 2013. Is There a Trade-Off between Inflation and Output Stabilization? American Economic Journal: Macroeconomics, Vol. 5, No. 2, pp. 1-31.

[30] Knell, M., 2013. Nominal and real wage rigidities, in theory and in Europe. Journal of Macroeconomics, Vol. 36C, pp. 89-105.

[31] Mortgage Banker Association, 2008. Lenders' Cost of Foreclosure, Policy Paper Congressional Education Series Briefing.

[32] Neumeyer, A. and F. Perri, 2005. Business cycles in emerging economies: the role of interest rates. Journal of Monetary Economics, Vol. 52, No. 2, pp. 345-380.

[33] Quint, D. and P. Rabanal, 2014. Monetary and Macroprudential Policy in an Estimated DSGE Model of the Euro Area. International Journal of Central Banking, Vol. 10, No.2, pp. 169-236.

[34] Quint, D., 2014. Is it Really More Dispersed? Measuring and Comparing the Stress From the Common Monetary Policy in the Euro Area?, Discussion Papers Free University Berlin, 13.

[35] Schmitt-Grohé, S. and M. Uribe, 2003. Closing Small Open Economy Models. Journal of International Economics, Vol. 61, No. 1, pp. 163-185.

[36] Smets, F. and R. Wouters, 2003. An Estimated Stochastic Dynamic General Equilibrium Model for the Euro Area. Journal of the European Economic Association, Vol. 1, No. 5, pp. 1123-1175.

[37] Stein, J., 2014. Incorporating Financial Stability Considerations into a Monetary Policy Framework. Speech delivered at the International Research Forum on Monetary Policy, Washington, D.C. March 21, 2014.

[38] Suh, H., 2012. Macroprudential Policy: Its Effects and Relationship to Monetary Policy. Federal Reserve Bank of Philadelphia Working Paper No. 12-28.

[39] Zhang, L., 2009. Bank Capital Regulation, the Lending Channel and Business Cycles. Discussion Paper Series 1: Economic Studies No. 2009,33, Deutsche Bundesbank, Research Centre. 


\section{A Appendix: Data and Sources}

Since we distinguish between two regions of the euro area, data for the core is obtained by aggregating data for France and Germany, while for the HBS countries data for Greece, Ireland, Italy, Portugal, and Spain are combined. The data is aggregated taking the economic size of the countries into account, using the household expenditure weights used by the Harmonised Index of Consumer Prices (HICP) for euro area countries. Since we exclude some countries of the euro area, we recompute the weights such that they always add up to one for the sample of countries we use. Some of the series start later than 2000q1 for some countries. When this is the case, aggregation for these quarters only takes into account available data, while weights are adjusted accordingly. All data is seasonally adjusted in case this has not been done by the original source.

HICP Inflation: Quarter on quarter log differences in the Harmonized Index of Consumer Prices (HICP), not seasonally adjusted by the source. Source: ECB.

Change in Real House Price Data: Quarter on quarter log differences in real housing prices. All data is provided by the OECD.

Real Private Consumption: Quarter on quarter log differences of final consumption of households and nonprofit institutions serving households (NPISH), seasonally adjusted by the source. Source: Eurostat.

Real Residential Investment: Quarter on quarter log differences of gross fixed capital formation in construction work for housing, seasonally adjusted by the source. Data for Greece, Ireland and Spain are seasonally adjusted using the X-12 ARIMA function in DMX. Source: Eurostat.

Real GDP: Quarter on quarter log differences of the real gross domestic product, seasonally adjusted by the source. Source: Eurostat.

ECB Interest Rate: 3-month Euribor, divided by 400. Source: ECB.

Household Outstanding Debt: Quarter on quarter log differences in household debt. The data are seasonally adjusted by the source only for France. For all other countries the data has been seasonally adjusted using the X-12 ARIMA function in DMX. Data for Ireland starts in 2002q1. Source: Eurostat.

Furthermore, for the calibration we use import data (Source: IMF Direction of Trade Statistics) and data on nominal household consumption (Source: IFS) to compute the fraction of

imported goods. The size of the non-durable sector is calculated as a ratio of gross value added by the construction sector to that of all branches (Source: Eurostat). The steady state ratio 
of defaults is calculated using non-performing loans as percent of total loans for the euro area between 2000-2011 (Source: World Bank World Development Indicators Database).

\section{B Appendix: Linearized Conditions}

In this section we present all log-linear conditions of the model. Upper case variables denote steady state values, lower case variables denote log-linear deviations from steady state values, and rest of the euro area variables are indicated with asterisks. Additionally, we make use of the following definitions:

- $Q_{t}$ denotes the relative price of durables in term of non-durables $\left(Q_{t} \equiv \frac{P_{t}^{D}}{P_{t}^{C}}\right)$,

- $\omega_{t}^{i}$ denotes the deviation of the real wages (nominal wages $W_{t}^{i}$ divided by the CPI index $P_{t}^{C}$, for $i=\{C, D\}$ ) from their steady state values,

- $\tilde{S}_{t}^{B}$ denotes real domestic debt expressed in terms of non-durable goods $\left(\tilde{S}_{t}^{B} \equiv \frac{S_{t}^{B}}{P_{t}^{C}}\right)$,

- $b_{t}$ denotes the deviations of foreign assets as percent of steady state non-durable output from its steady state value of zero $\left(b_{t} \equiv \frac{B_{t}}{P_{t}^{C} Y^{C}}\right)$,

- $\hat{\bar{\omega}}_{t}^{i}$ and $\hat{\sigma}_{\omega, t}$ denote the deviations from their steady state values for the threshold $\bar{\omega}_{t}^{i}$ and the variance $\bar{\sigma}_{\omega, t}$, respectively (for $i=\{a, p\}$ ),

- The terms of trade is given by $T_{t}=\frac{P_{F, t}}{P_{H, t}}$,

- The average interest rate of those who default is defined as $R_{t}^{D}=G\left(\bar{\omega}_{t-1}^{P}, \sigma_{\omega, t-1}\right) P_{t}^{D} D_{t}^{B} / S_{t-1}^{B}$,

- Aggregate non-durable consumption is given by $C_{t}^{T O T}=\lambda C_{t}+(1-\lambda) C_{t}^{B}$.

In addition, since the model includes a unit root shock in technology, the following variables inherit the same unit root behavior:

- consumption of non-durables (by agent and aggregate, including domestically produced and imported): $C_{t}, C_{t}^{B}, C_{t}^{T O T}, C_{H, t}, C_{F, t}, C_{t}^{*}, C_{t}^{B^{*}}, C_{t}^{T O T^{*}}, C_{H, t}^{*}, C_{F, t}^{*}$,

- residential investment and the housing stock of both borrowers and savers: $I_{t}, I_{t}^{B}, D_{t}, D_{t}^{B}, I_{t}^{*}$, $I_{t}^{B^{*}}, D_{t}^{*}, D_{t}^{B^{*}}$,

- real wages in both sectors: $\omega_{t}^{C}, \omega_{t}^{D}, \omega_{t}^{C^{*}}, \omega_{t}^{D^{*}}$, 
- the production of durable and non-durable goods and real GDP: $Y_{t}^{C}, Y_{t}^{D}, Y_{t}, Y_{t}^{C^{*}}, Y_{t}^{D^{*}}$, and $Y_{t}^{*}$,

- and real credit $\tilde{S}_{t}^{B}, \tilde{S}_{t}^{B^{*}}$.

Hence, we normalize all these real variables by the EMU-level of technology $A_{t}$. For these variables, lower case variables denote deviations from steady state values of normalized variables. That is, $c_{t}=\log \left(C_{t} / A_{t}\right)-\log (\overline{C / A})$ and so on. Rest of the euro area region variables are normalized in the same way. For instance, $c_{t}^{*}=\log \left(C_{t}^{*} / A_{t}\right)-\log \left(\overline{C^{*} / A}\right)$.

\section{Home Region}

From the optimal decision by savers we get the following: ${ }^{42}$

$$
q_{t}+\xi_{t}^{C}-\frac{c_{t}-\varepsilon\left(c_{t-1}-\varepsilon_{t}^{A}\right)}{1-\varepsilon}+\psi\left(i_{t}-i_{t-1}+\varepsilon_{t}^{A}\right)=E_{t} \varrho_{t+1}+\beta \psi\left(E_{t} i_{t+1}-i_{t}\right),
$$

where $\psi=\digamma "($.$) and \varrho_{t}$ is the normalized Lagrange multiplier associated with the law of motion of the housing stock (10) for savers, and

$$
\begin{gathered}
{[1-\beta(1-\delta)]\left(\xi_{t}^{D}-d_{t}\right)=\varrho_{t}-\beta(1-\delta) E_{t} \varrho_{t+1},} \\
\varepsilon\left(\Delta c_{t}+\varepsilon_{t}^{A}\right)=E_{t} \Delta c_{t+1}-(1-\varepsilon)\left(r_{t}+E_{t} \Delta \xi_{t+1}^{C}-E_{t} \Delta p_{t+1}^{C}\right) .
\end{gathered}
$$

The marginal rate of substitution between consumption and leisure for savers when they work in the non-durable sector is given by:

$$
m r s_{t}^{C}=\frac{c_{t}-\varepsilon\left(c_{t-1}-\varepsilon_{t}^{A}\right)}{1-\varepsilon}-\xi_{t}^{C}+\left[\left(\varphi-\iota_{L}\right) \alpha+\iota_{L}\right] l_{t}^{C}+\left(\varphi-\iota_{L}\right)(1-\alpha) l_{t}^{D},
$$

while when they work in the non-durable sector it is:

$$
m r s_{t}^{D}=\frac{c_{t}-\varepsilon\left(c_{t-1}-\varepsilon_{t}^{A}\right)}{1-\varepsilon}-\xi_{t}^{C}+\left[\left(\varphi-\iota_{L}\right)(1-\alpha)+\iota_{L}\right] l_{t}^{D}+\left(\varphi-\iota_{L}\right) \alpha l_{t}^{C} .
$$

The same conditions for borrowers are given by:

$$
m r s_{t}^{C, B}=\frac{c_{t}^{B}-\varepsilon\left(c_{t-1}^{B}-\varepsilon_{t}^{A}\right)}{1-\varepsilon}-\xi_{t}^{C}+\left[\left(\varphi-\iota_{L}\right) \alpha+\iota_{L}\right] l_{t}^{B, C}+\left(\varphi-\iota_{L}\right)(1-\alpha) l_{t}^{B, D},
$$

\footnotetext{
${ }^{42}$ Since all households behave the same way, we henceforth drop the $j$ superscript.
} 
while when they work in the non-durable sector it is:

$$
m r s_{t}^{D, B}=\frac{c_{t}-\varepsilon\left(c_{t-1}-\varepsilon_{t}^{A}\right)}{1-\varepsilon}-\xi_{t}^{C}+\left[\left(\varphi-\iota_{L}\right)(1-\alpha)+\iota_{L}\right] l_{t}^{B, D}+\left(\varphi-\iota_{L}\right) \alpha l_{t}^{B, C} .
$$

We assume that wages are set for each sector by a union that negotiates on behalf of the savers. The resulting wage Phillips Curves are given by:

$\omega_{t}^{C}-\omega_{t-1}^{C}+\varepsilon_{t}^{A}+\Delta p_{t}^{C}-\varphi_{C, W} \Delta p_{t-1}^{C}=\beta E_{t}\left(\omega_{t+1}^{C}-\omega_{t}^{C}+\Delta p_{t+1}^{C}-\varphi_{C, W} \Delta p_{t}^{C}\right)+\kappa^{C, W}\left(m r s_{t}^{C}-\omega_{t}^{C}\right)$

where $\kappa^{C, W}=\frac{\left(1-\theta_{C, W}\right)\left(1-\beta \theta_{C, W}\right)}{\theta_{C, W}}$, and

$\omega_{t}^{D}-\omega_{t-1}^{D}+\varepsilon_{t}^{A}+\Delta p_{t}^{C}-\varphi_{D, W} \Delta p_{t-1}^{C}=\beta E_{t}\left(\omega_{t+1}^{D}-\omega_{t}^{D}+\Delta p_{t+1}^{C}-\varphi_{D, W} \Delta p_{t}^{C}\right)+\kappa^{D, W}\left(m r s_{t}^{D}-\omega_{t}^{D}\right)$

where $\kappa^{D, W}=\frac{\left(1-\theta_{D, W}\right)\left(1-\beta \theta_{D, W}\right)}{\theta_{D, W}}$.

We assume that borrowers are also on board for this decision, because their labor supply schedules are such that marginal rates of substitution are equalized between types of agents (however, consumption levels and hours worked do not):

$$
\omega_{t}^{C}=\operatorname{mrs}_{t}^{C, B}
$$

and

$$
\omega_{t}^{D}=m r s_{t}^{D, B}
$$

The same conditions for borrowers are:

$$
q_{t}+\xi_{t}^{C}-\frac{c_{t}^{B}-\varepsilon^{B}\left(c_{t-1}^{B}-\varepsilon_{t}^{A}\right)}{1-\varepsilon^{B}}+\psi\left(i_{t}^{B}-i_{t-1}^{B}+\varepsilon_{t}^{A}\right)=E_{t} \varrho_{t+1}^{B}+\beta^{B} \psi\left(E_{t} i_{t+1}^{B}-i_{t}^{B}\right),
$$

with $\varrho_{t}^{B}$ being the Lagrange multiplier associated with the law of motion of the housing stock (10) for borrowers, and

$$
\left[1-\beta^{B}(1-\delta)\right]\left(\xi_{t}^{D}-d_{t}^{B}\right)=\varrho_{t}^{B}-\beta^{B}(1-\delta) E_{t} \varrho_{t+1}^{B},
$$




$$
\begin{aligned}
& \varepsilon^{B}\left(\Delta c_{t}^{B}+\varepsilon_{t}^{A}\right) \\
= & E_{t} \Delta c_{t+1}^{B}-\left(1-\varepsilon^{B}\right)\left(\beta^{B} R^{D} E_{t} r_{t+1}^{D}+E_{t} \Delta \xi_{t+1}^{C}-E_{t} \Delta p_{t+1}^{C}\right) \\
& -\left(1-\varepsilon^{B}\right) \beta^{B} R^{L}\left[1-F\left(\bar{\omega}, \sigma_{\omega}\right)\right]\left(r_{t}^{L}-\frac{F_{\omega}\left(\bar{\omega}, \sigma_{\omega}\right) \bar{\omega}}{1-F\left(\bar{\omega}, \sigma_{\omega}\right)} \hat{\bar{\omega}}_{t}^{a}-\frac{F_{\sigma_{\omega}}\left(\bar{\omega}, \sigma_{\omega}\right) \sigma_{\omega}}{1-F\left(\bar{\omega}, \sigma_{\omega}\right)} \hat{\sigma}_{\omega, t}\right),
\end{aligned}
$$

with the interest rate for those who default is given by:

$$
r_{t}^{D}=d_{t}^{B}-\tilde{s}_{t-1}^{B}+\frac{G_{\omega}\left(\bar{\omega}, \sigma_{\omega}\right) \bar{\omega}_{\hat{\bar{\omega}}}^{p}}{G\left(\bar{\omega}, \sigma_{\omega}\right)}+\frac{G_{\sigma_{\omega}}\left(\bar{\omega}, \sigma_{\omega}\right) \sigma_{\omega}}{G\left(\bar{\omega}, \sigma_{\omega}\right)} \hat{\sigma}_{\omega, t-1}+q_{t}+\Delta p_{t}^{C}+\varepsilon_{t}^{A}
$$

The budget constraint of borrowers is:

$$
\begin{aligned}
& C^{B} c_{t}^{B}+\delta D^{B}\left(q_{t}+i_{t}^{B}\right)+R^{D} \tilde{S}^{B}\left[r_{t}^{D}+\tilde{s}_{t-1}^{B}-\Delta p_{t}^{C}-\varepsilon_{t}^{A}\right] \\
& +\left[1-F\left(\bar{\omega}, \sigma_{\omega}\right)\right] R^{L} \tilde{S}^{B}\left[r_{t-1}^{L}+\tilde{s}_{t-1}^{B}-\Delta p_{t}^{C}-\varepsilon_{t}^{A}\right] \\
& -\left[1-F\left(\bar{\omega}, \sigma_{\omega}\right)\right] R^{L} \tilde{S}^{B}\left[\frac{F_{\omega}\left(\bar{\omega}, \sigma_{\omega}\right) \bar{\omega}}{1-F\left(\bar{\omega}, \sigma_{\omega}\right)} \hat{\bar{\omega}}_{t-1}^{p}+\frac{F_{\sigma_{\omega}}\left(\bar{\omega}, \sigma_{\omega}\right) \sigma_{\omega}}{1-F\left(\bar{\omega}, \sigma_{\omega}\right)} \hat{\sigma}_{\omega, t-1}\right] \\
= & \tilde{S}^{B} \tilde{s}_{t}^{B}+\alpha W L^{B}\left(\omega_{t}^{C}+l_{t}^{B, C}\right)+(1-\alpha) W L^{B}\left(\omega_{t}^{D}+l_{t}^{B, D}\right) .
\end{aligned}
$$

The lending rate for borrowers is determined by the participation constraint of financial intermediaries:

$$
\begin{aligned}
& \frac{1}{\beta} \tilde{S}^{B}\left(r_{t}+\tilde{s}_{t}^{B}\right) \\
= & (1-\mu) D^{B} G\left(\bar{\omega}, \sigma_{\omega}\right)\left[\frac{G_{\omega}\left(\bar{\omega}, \sigma_{\omega}\right) \bar{\omega}}{G\left(\bar{\omega}, \sigma_{\omega}\right)} \hat{\bar{\omega}}_{t}^{a}+\frac{G_{\sigma_{\omega}}\left(\bar{\omega}, \sigma_{\omega}\right) \sigma_{\omega}}{G\left(\bar{\omega}, \sigma_{\omega}\right)} \hat{\sigma}_{\omega, t}\right] \\
& +(1-\mu) D^{B} G\left(\bar{\omega}, \sigma_{\omega}\right)\left[E_{t} q_{t+1}+E_{t} d_{t+1}^{B}+E_{t} \Delta p_{t+1}^{C}\right] \\
& +\left[1-F\left(\bar{\omega}, \sigma_{\omega}\right)\right] R^{L} \tilde{S}^{B}\left[r_{t}^{L}+\tilde{s}_{t}^{B}-\frac{F_{\omega}\left(\bar{\omega}, \sigma_{\omega}\right) \bar{\omega}}{1-F\left(\bar{\omega}, \sigma_{\omega}\right)} \hat{\bar{\omega}}_{t}^{a}-\frac{F_{\sigma_{\omega}}\left(\bar{\omega}, \sigma_{\omega}\right) \sigma_{\omega}}{1-F\left(\bar{\omega}, \sigma_{\omega}\right)} \hat{\sigma}_{\omega, t}\right] .
\end{aligned}
$$

The ex-ante and ex-post default threshold is:

$$
\begin{aligned}
\hat{\bar{\omega}}_{t}^{a}+E_{t}\left[q_{t+1}+d_{t+1}^{B}\right] & =r_{t}^{L}+\tilde{s}_{t}^{B}-E_{t} \Delta p_{t+1}^{C}, \\
\hat{\bar{\omega}}_{t-1}^{p}+q_{t}+d_{t}^{B} & =r_{t-1}^{L}+\tilde{s}_{t-1}^{B}-\Delta p_{t}^{C}-\varepsilon_{t}^{A} .
\end{aligned}
$$

The evolution of domestic and imported non-durable consumption is:

$$
\begin{gathered}
c_{H, t}=\iota_{C}(1-\tau) t_{t}+c_{t}^{T O T}, \\
c_{F, t}=-\iota_{C} \tau t_{t}+c_{t}^{T O T},
\end{gathered}
$$


where aggregate non-durable consumption is:

$$
\left[\lambda C+(1-\lambda) C^{B}\right] c_{t}^{T O T}=\lambda C c_{t}+(1-\lambda) C^{B} c_{t}^{B}
$$

The production functions are given by:

$$
\begin{aligned}
& y_{t}^{C}=z_{t}^{C}+l_{t}^{C, T O T}, \\
& y_{t}^{D}=z_{t}^{D}+l_{t}^{D, T O T},
\end{aligned}
$$

where total hours in each sector are given by:

$$
\begin{aligned}
& {\left[\lambda L^{C}+(1-\lambda) L^{B, C}\right] l_{t}^{C, T O T}=\lambda L^{C} l_{t}^{C}+(1-\lambda) L^{B, C} l_{t}^{B, C}} \\
& {\left[\lambda L^{D}+(1-\lambda) L^{B, D}\right] l_{t}^{D, T O T}=\lambda L^{D} l_{t}^{D}+(1-\lambda) L^{B, D} l_{t}^{B, D} .}
\end{aligned}
$$

The CPI is given by:

$$
\Delta p_{t}^{C}=\tau \Delta p_{H, t}+(1-\tau) \Delta p_{F, t} .
$$

The relative price of housing is:

$$
q_{t}=q_{t-1}+\Delta p_{t}^{D}-\Delta p_{t}^{C},
$$

and the pricing equations are given by:

$$
\Delta p_{t}^{H}-\varphi_{C} \Delta p_{t-1}^{H}=\beta E_{t}\left(\Delta p_{t+1}^{H}-\varphi_{C} \Delta p_{t}^{H}\right)+\kappa^{C}\left[\omega_{t}^{C}+(1-\tau) t_{t}-z_{t}^{C}\right]+\varepsilon_{t}^{\mu^{C}}
$$

where $\kappa^{C}=\frac{\left(1-\theta_{C}\right)\left(1-\beta \theta_{C}\right)}{\theta_{C}}, \varepsilon_{t}^{\mu^{C}}$ is an iid price mark-up shock, and

$$
\Delta p_{t}^{D}-\varphi_{D} \Delta p_{t-1}^{D}=\beta E_{t}\left(\Delta p_{t+1}^{D}-\varphi_{D} \Delta p_{t}^{D}\right)+\kappa^{D}\left[\omega_{t}^{D}-q_{t}-z_{t}^{D}\right],
$$

where $\kappa^{D}=\frac{\left(1-\theta_{D}\right)\left(1-\beta \theta_{D}\right)}{\theta_{D}}$.

The market clearing conditions for the non-durable goods sector reads as follows:

$$
y_{t}^{C}=\tau c_{H, t}+\frac{(1-n)\left(1-\tau^{*}\right)}{n} c_{H, t}^{*}
$$

Aggregate investment expenditures equal production of investment goods:

$$
y_{t}^{D}=\frac{\lambda \delta D i_{t}+(1-\lambda) \delta D^{B} i_{t}^{B}}{\lambda \delta D+(1-\lambda) \delta D^{B}}
$$


and the law of motion of the two types of housing stocks are given by:

$$
\begin{aligned}
& d_{t}=(1-\delta) d_{t-1}+\delta i_{t-1}-\varepsilon_{t}^{A}, \\
& d_{t}^{B}=(1-\delta) d_{t-1}^{B}+\delta i_{t-1}^{B}-\varepsilon_{t}^{A} .
\end{aligned}
$$

Aggregated output is given by:

$$
y_{t}=\alpha y_{t}^{C}+(1-\alpha)\left(y_{t}^{D}+q_{t}\right) .
$$

\section{Rest of the Euro Area Region}

Here, we present the conditions of the model for the rest of the euro area region. From the optimal decision of savers we get the following:

$$
\begin{gathered}
q_{t}^{*}+\xi_{t}^{C^{*}}-\frac{c_{t}^{*}-\varepsilon\left(c_{t-1}^{*}-\varepsilon_{t}^{A}\right)}{1-\varepsilon}+\psi\left(i_{t}^{*}-i_{t-1}^{*}+\varepsilon_{t}^{A}\right)=E_{t} \varrho_{t+1}^{*}+\beta \psi\left(E_{t} i_{t+1}^{*}-i_{t}^{*}\right), \\
{[1-\beta(1-\delta)]\left(\xi_{t}^{D^{*}}-d_{t}^{*}\right)=\varrho_{t}^{*}-\beta(1-\delta) E_{t} \varrho_{t+1}^{*},} \\
m\left(\Delta c_{t}^{*}+\varepsilon_{t}^{A}\right)=E_{t} \Delta c_{t+1}^{*}-(1-\varepsilon)\left(r_{t}^{*}+E_{t} \Delta \xi_{t+1}^{C^{*}}-E_{t} \Delta p_{t+1}^{C^{*}}\right), \\
m r s_{t}^{C^{*}}=\frac{c_{t}^{*}-\varepsilon\left(c_{t-1}^{*}-\varepsilon_{t}^{A}\right)}{1-\varepsilon}-\xi_{t}^{C^{*}}+\left[\left(\varphi-\iota_{L}\right) \alpha+\iota_{L}\right] l_{t}^{C^{*}}+\left(\varphi-\iota_{L}\right)(1-\alpha) l_{t}^{D^{*}} \\
m r s_{t}^{D^{*}}=\frac{c_{t}^{*}-\varepsilon\left(c_{t-1}^{*}-\varepsilon_{t}^{A}\right)}{1-\varepsilon}-\xi_{t}^{C^{*}}+\left[\left(\varphi-\iota_{L}\right)(1-\alpha)+\iota_{L}\right] l_{t}^{D^{*}}+\left(\varphi-\iota_{L}\right) \alpha l_{t}^{C^{*}} \\
m r s_{t}^{C, B^{*}}=\frac{c_{t}^{B^{*}}-\varepsilon\left(c_{t-1}^{B^{*}}-\varepsilon_{t}^{A}\right)}{1-\varepsilon}-\xi_{t}^{C^{*}}+\left[\left(\varphi-\iota_{L}\right) \alpha+\iota_{L}\right] l_{t}^{B, C^{*}}+\left(\varphi-\iota_{L}\right)(1-\alpha) l_{t}^{B, D^{*}}
\end{gathered}
$$


We assume that wages are set for each sector by a union that negotiates on behalf of the savers. The resulting wage Phillips Curves are given by:

$\omega_{t}^{C^{*}}-\omega_{t-1}^{C^{*}}+\varepsilon_{t}^{A}+\Delta p_{t}^{C^{*}}-\varphi_{C, W}^{*} \Delta p_{t-1}^{C^{*}}=\beta E_{t}\left(\omega_{t+1}^{C^{*}}-\omega_{t}^{C^{*}}+\Delta p_{t+1}^{C^{*}}-\varphi_{C, W}^{*} \Delta p_{t}^{C^{*}}\right)+\kappa^{C, W^{*}}\left(m r s_{t}^{C^{*}}-\omega_{t}^{C^{*}}\right)$

where $\kappa^{C, W^{*}}=\frac{\left(1-\theta_{C, W}^{*}\right)\left(1-\beta \theta_{C, W}^{*}\right)}{\theta_{C, W}^{*}}$, and

$\omega_{t}^{D^{*}}-\omega_{t-1}^{D^{*}}+\varepsilon_{t}^{A}+\Delta p_{t}^{C^{*}}-\varphi_{D, W}^{*} \Delta p_{t-1}^{C^{*}}=\beta E_{t}\left(\omega_{t+1}^{D^{*}}-\omega_{t}^{D^{*}}+\Delta p_{t+1}^{C^{*}}-\varphi_{D, W}^{*} \Delta p_{t}^{C^{*}}\right)+\kappa^{D, W^{*}}\left(m r s_{t}^{D^{*}}-\omega_{t}^{D^{*}}\right)$

where $\kappa^{D, W^{*}}=\frac{\left(1-\theta_{D, W}^{*}\right)\left(1-\beta \theta_{D, W}^{*}\right)}{\theta_{D, W}^{*}}$.

We assume that borrowers are also on board for this decision, because their labor supply schedules are such that marginal rates of substitution are equalized between types of agents (however, consumption levels and hours worked do not):

$$
\omega_{t}^{C^{*}}=\operatorname{mrs}_{t}^{C, B^{*}}
$$

and

$$
\omega_{t}^{D^{*}}=\operatorname{mrs}_{t}^{D, B^{*}}
$$

The same conditions for borrowers are:

$$
\begin{gathered}
q_{t}^{*}+\xi_{t}^{C^{*}}-\frac{c_{t}^{B^{*}}-\varepsilon^{B}\left(c_{t-1}^{B^{*}}-\varepsilon_{t}^{A}\right)}{1-\varepsilon^{B^{*}}}+\psi\left(i_{t}^{B^{*}}-i_{t-1}^{B^{*}}+\varepsilon_{t}^{A}\right)=E_{t} \varrho_{t+1}^{B^{*}}+\beta^{B} \psi\left(E_{t} i_{t+1}^{B^{*}}-i_{t}^{B^{*}}\right), \\
{\left[1-\beta^{B}(1-\delta)\right]\left(\xi_{t}^{D^{*}}-d_{t}^{B^{*}}\right)=\varrho_{t}^{B^{*}}-\beta^{B}(1-\delta) E_{t} \varrho_{t+1}^{B^{*}},} \\
=\varepsilon^{B}\left(\Delta c_{t}^{B^{*}}+\varepsilon_{t}^{A}\right) \\
\quad E_{t} \Delta c_{t+1}^{B^{*}}-\left(1-\varepsilon^{B}\right)\left(\beta^{B} R^{D^{*}} E_{t} r_{t+1}^{D^{*}}+E_{t} \Delta \xi_{t+1}^{C^{*}}-E_{t} \Delta p_{t+1}^{C^{*}}\right) \\
-\left(1-\varepsilon^{B}\right) \beta^{B} R^{L *}\left[1-F\left(\bar{\omega}, \sigma_{\omega}\right)\right]\left(r_{t}^{L *}-\frac{F_{\omega}\left(\bar{\omega}, \sigma_{\omega}\right) \bar{\omega}}{1-F\left(\bar{\omega}, \sigma_{\omega}\right)} \hat{\bar{\omega}}_{t}^{a *}-\frac{F_{\sigma_{\omega}}\left(\bar{\omega}, \sigma_{\omega}\right) \sigma_{\omega}}{1-F\left(\bar{\omega}, \sigma_{\omega}\right)} \hat{\sigma}_{\omega, t}^{*}\right),
\end{gathered}
$$




$$
r_{t}^{D^{*}}=d_{t}^{B^{*}}-\tilde{s}_{t-1}^{B^{*}}+\frac{G_{\omega}\left(\bar{\omega}, \sigma_{\omega}\right) \bar{\omega}}{G\left(\bar{\omega}, \sigma_{\omega}\right)} \hat{\bar{\omega}}_{t-1}^{p *}+\frac{G_{\sigma_{\omega}}\left(\bar{\omega}, \sigma_{\omega}\right) \sigma_{\omega}}{G\left(\bar{\omega}, \sigma_{\omega}\right)} \hat{\sigma}_{\omega, t-1}^{*}+q_{t}^{*}+\Delta p_{t}^{C^{*}}+\varepsilon_{t}^{A},
$$

The budget constraint of borrowers is:

$$
\begin{aligned}
& C^{B *} c_{t}^{B *}+\delta D^{B *}\left(q_{t}^{*}+i_{t}^{B *}\right)+R^{D *} \tilde{S}^{B *}\left[r_{t}^{D *}+\tilde{s}_{t-1}^{B *}-\Delta p_{t}^{C *}-\varepsilon_{t}^{A}\right] \\
& +\left[1-F\left(\bar{\omega}, \sigma_{\omega}\right)\right] R^{L *} \tilde{S}^{B *}\left[r_{t-1}^{L *}+\tilde{s}_{t-1}^{B *}-\Delta p_{t}^{C *}-\varepsilon_{t}^{A}\right] \\
& -\left[1-F\left(\bar{\omega}, \sigma_{\omega}\right)\right] R^{L *} \tilde{S}^{B *}\left[\frac{F_{\omega}\left(\bar{\omega}, \sigma_{\omega}\right) \bar{\omega}}{1-F\left(\bar{\omega}, \sigma_{\omega}\right)} \hat{\bar{\omega}}_{t-1}^{p *}+\frac{F_{\sigma_{\omega}}\left(\bar{\omega}, \sigma_{\omega}\right) \sigma_{\omega}}{1-F\left(\bar{\omega}, \sigma_{\omega}\right)} \hat{\sigma}_{\omega, t-1}^{*}\right] \\
= & \tilde{S}^{B *} \tilde{s}_{t}^{B *}+\alpha W^{*} L^{B *}\left(\omega_{t}^{C *}+l_{t}^{B, C *}\right)+(1-\alpha) W^{*} L^{B *}\left(\omega_{t}^{D *}+l_{t}^{B, D *}\right) .
\end{aligned}
$$

The participation constraint of financial intermediaries:

$$
\begin{aligned}
& \frac{1}{\beta} \tilde{S}^{B^{*}}\left(r_{t}^{*}+\tilde{s}_{t}^{B^{*}}\right) \\
= & (1-\mu) D^{B^{*}} G\left(\bar{\omega}, \sigma_{\omega}\right)\left[\frac{G_{\omega}\left(\bar{\omega}, \sigma_{\omega}\right) \bar{\omega}}{G\left(\bar{\omega}, \sigma_{\omega}\right)} \hat{\bar{\omega}}_{t}^{a *}+\frac{G_{\sigma_{\omega}}\left(\bar{\omega}, \sigma_{\omega}\right) \sigma_{\omega}}{G\left(\bar{\omega}, \sigma_{\omega}\right)} \hat{\sigma}_{\omega, t}^{*}\right] \\
& +(1-\mu) D^{B^{*}} G\left(\bar{\omega}, \sigma_{\omega}\right)\left[E_{t} q_{t+1}^{*}+E_{t} d_{t+1}^{B^{*}}+E_{t} \Delta p_{t+1}^{C^{*}}\right] \\
& +\left[1-F\left(\bar{\omega}, \sigma_{\omega}\right)\right] R^{L *} \tilde{S}^{B^{*}}\left[r_{t}^{L *}+\tilde{s}_{t}^{B^{*}}-\frac{F_{\omega}\left(\bar{\omega}, \sigma_{\omega}\right) \bar{\omega}}{1-F\left(\bar{\omega}, \sigma_{\omega}\right)} \hat{\bar{\omega}}_{t}^{a *}-\frac{F_{\sigma_{\omega}}\left(\bar{\omega}, \sigma_{\omega}\right) \sigma_{\omega}}{1-F\left(\bar{\omega}, \sigma_{\omega}\right)} \hat{\sigma}_{\omega, t}^{*}\right] .
\end{aligned}
$$

The ex-ante and ex-post default threshold is:

$$
\begin{aligned}
\hat{\bar{\omega}}_{t}^{a *}+E_{t}\left[q_{t+1}^{*}+d_{t+1}^{B^{*}}\right] & =r_{t}^{L *}+\tilde{s}_{t}^{B^{*}}-E_{t} \Delta p_{t+1}^{C^{*}}, \\
\hat{\bar{\omega}}_{t-1}^{p *}+q_{t}^{*}+d_{t}^{B^{*}} & =r_{t-1}^{L *}+\tilde{s}_{t-1}^{B^{*}}-\Delta p_{t}^{C^{*}}-\varepsilon_{t}^{A} .
\end{aligned}
$$

The evolution of domestic and imported non-durable consumption is:

$$
\begin{gathered}
c_{H, t}^{*}=\iota_{C} \tau^{*} t_{t}+c_{t}^{T O T^{*}}, \\
c_{F, t}^{*}=-\iota_{C}\left(1-\tau^{*}\right) t_{t}+c_{t}^{T O T^{*}},
\end{gathered}
$$

where aggregate non-durable consumption is:

$$
\left[\lambda C^{*}+(1-\lambda) C^{B^{*}}\right] c_{t}^{T O T^{*}}=\lambda C^{*} c_{t}^{*}+(1-\lambda) C^{B^{*}} c_{t}^{B^{*}}
$$

The production functions are given by:

$$
\begin{aligned}
& y_{t}^{C^{*}}=z_{t}^{C^{*}}+l_{t}^{C, T O T^{*}} \\
& y_{t}^{D^{*}}=z_{t}^{D^{*}}+l_{t}^{D, T O T^{*}}
\end{aligned}
$$


where total hours in each sector are given by:

$$
\begin{gathered}
{\left[\lambda L^{C^{*}}+(1-\lambda) L^{B, C^{*}}\right] l_{t}^{C, T O T^{*}}=\lambda L^{C^{*}} l_{t}^{C^{*}}+(1-\lambda) L^{B, C^{*}} l_{t}^{B, C^{*}},} \\
{\left[\lambda L^{D^{*}}+(1-\lambda) L^{B, D^{*}}\right] l_{t}^{D, T O T^{*}}=\lambda L^{D^{*}} l_{t}^{D^{*}}+(1-\lambda) L^{B, D^{*}} l_{t}^{B, D^{*}} .}
\end{gathered}
$$

The CPI is:

$$
\Delta p_{t}^{C^{*}}=\left(1-\tau^{*}\right) \Delta p_{H, t}+\tau^{*} \Delta p_{F, t} .
$$

The relative price of housing is:

$$
q_{t}^{*}=q_{t-1}^{*}+\Delta p_{t}^{D^{*}}-\Delta p_{t}^{C^{*}}
$$

and the pricing equations are given by:

$$
\Delta p_{t}^{F}-\varphi_{C}^{*} \Delta p_{t-1}^{F}=\beta E_{t}\left(\Delta p_{t+1}^{F}-\varphi_{C}^{*} \Delta p_{t}^{F}\right)+\kappa^{C^{*}}\left[\omega_{t}^{C^{*}}-\left(1-\tau^{*}\right) t_{t}-z_{t}^{C^{*}}\right]+\varepsilon_{t}^{\mu^{C^{*}}}
$$

where $\kappa^{C^{*}}=\frac{\left(1-\theta_{C}^{*}\right)\left(1-\beta \theta_{C}^{*}\right)}{\theta_{C}^{*}}, \varepsilon_{t}^{\mu^{C^{*}}}$ is an iid price mark-up shock, and

$$
\Delta p_{t}^{D^{*}}-\varphi_{D}^{*} \Delta p_{t-1}^{D^{*}}=\beta E_{t}\left(\Delta p_{t+1}^{D^{*}}-\varphi_{D}^{*} \Delta p_{t}^{D^{*}}\right)+\kappa^{D^{*}}\left[\omega_{t}^{D^{*}}-q_{t}^{*}-z_{t}^{D^{*}}\right],
$$

where $\kappa^{D^{*}}=\frac{\left(1-\theta_{D}^{*}\right)\left(1-\beta \theta_{D}^{*}\right)}{\theta_{D}^{*}}$.

The market clearing conditions for the non-durable goods sector reads as follows:

$$
y_{t}^{C^{*}}=\tau^{*} c_{F, t}^{*}+\frac{n(1-\tau)}{1-n} c_{F, t}
$$

Aggregate investment expenditures equal production of investment goods:

$$
y_{t}^{D^{*}}=\frac{\lambda \delta D^{*} i_{t}^{*}+(1-\lambda) \delta D^{B^{*}} i_{t}^{B^{*}}}{\lambda \delta D^{*}+(1-\lambda) \delta D^{B^{*}}}
$$

and the law of motion of the two types of housing stocks are given by:

$$
\begin{gathered}
d_{t}^{*}=(1-\delta) d_{t-1}^{*}+\delta i_{t-1}^{*}-\varepsilon_{t}^{A}, \\
d_{t}^{B^{*}}=(1-\delta) d_{t-1}^{B^{*}}+\delta i_{t-1}^{B^{*}}-\varepsilon_{t}^{A} .
\end{gathered}
$$

Aggregated output is given by:

$$
y_{t}^{*}=\alpha^{*} y_{t}^{C^{*}}+\left(1-\alpha^{*}\right)\left(y_{t}^{D^{*}}+q_{t}^{*}\right) .
$$




\section{Euro Area Variables and Other Equations}

The relationship between the two nominal interest rates in the home and rest of the euro area regions is as follows:

$$
r_{t}^{*}=r_{t}+\beta\left(\kappa_{b} b_{t}+\vartheta_{t}\right)
$$

The evolution of net foreign assets is:

$$
\lambda b_{t}=\lambda \frac{1}{\beta} b_{t-1}+\frac{(1-n)\left(1-\tau^{*}\right)}{n}\left(c_{H, t}^{*}-t_{t}\right)-(1-\tau) c_{F, t},
$$

where we have used the fact that $t_{t}=-t_{t}^{*}$, and the evolution of the terms of trade is given by:

$$
t_{t}=t_{t-1}+\Delta p_{t}^{F}-\Delta p_{t}^{H}
$$

The monetary policy Taylor rule conducted by the ECB reads:

$$
r_{t}=\gamma_{R} r_{t-1}+\left(1-\gamma_{R}\right)\left[\gamma_{\pi} \Delta p_{t}^{E M U}+\gamma_{y}\left(y_{t}^{E M U}-y_{t-1}^{E M U}-\varepsilon_{t}^{A}\right)\right]+\varepsilon_{t}^{m},
$$

where the euro area CPI and output is given by:

$$
\begin{aligned}
\Delta p_{t}^{E M U} & =n \Delta p_{t}^{C}+(1-n) \Delta p_{t}^{C^{*}} \\
y_{t}^{E M U} & =n y_{t}+(1-n) y_{t}^{*} .
\end{aligned}
$$

The measurement equation that links GDP in the model and in the data is:

$$
\begin{aligned}
& g d p_{t}=(1-\bar{g}) y_{t}+\bar{g}\left(g_{t}\right) \\
& g d p_{t}^{*}=\left(1-\bar{g}^{*}\right) y_{t}^{*}+\bar{g}^{*}\left(g_{t}^{*}\right)
\end{aligned}
$$




\section{Shock Processes}

All shocks included in the model evolve according to:

$$
\begin{aligned}
\xi_{t}^{C} & =\rho_{\xi, H} \xi_{t-1}^{C}+\varepsilon_{t}^{\xi, C}, \\
\xi_{t}^{C^{*}} & =\rho_{\xi, H} \xi_{t-1}^{C^{*}}+\varepsilon_{t}^{\xi, C^{*}} \\
\xi_{t}^{D} & =\rho_{\xi, D} \xi_{t-1}^{D}+\varepsilon_{t}^{\xi, D}+\varepsilon_{t}^{\xi, D, C O M}, \\
\xi_{t}^{D^{*}} & =\rho_{\xi, D} \xi_{t-1}^{D^{*}}+\varepsilon_{t}^{\xi, D^{*}}+\varepsilon_{t}^{\xi, D, C O M}, \\
z_{t}^{C} & =\rho_{Z, C} z_{t-1}^{C}+\varepsilon_{t}^{Z, C}+\varepsilon_{t}^{Z, C, C O M}, \\
z_{t}^{C^{*}} & =\rho_{Z, C} z_{t-1}^{C^{*}}+\varepsilon_{t}^{Z, C^{*}}+\varepsilon_{t}^{Z, C, C O M}, \\
z_{t}^{D} & =\rho_{Z, D} z_{t-1}^{D}+\varepsilon_{t}^{Z, D} \\
z_{t}^{D^{*}} & =\rho_{Z, D} z_{t-1}^{D^{*}}+\varepsilon_{t}^{Z, D^{*}} \\
\sigma_{\omega, t} & =\left(1-\rho_{\sigma \omega}\right) \bar{\sigma}_{\omega}+\rho_{\sigma \omega} \sigma_{\omega, t-1}+u_{\omega, t}, \\
\sigma_{\omega, t}^{*} & =\left(1-\rho_{\sigma \omega}\right) \bar{\sigma}_{\omega}+\rho_{\sigma \omega} \sigma_{\omega, t-1}^{*}+u_{\omega, t}^{*} \\
g_{t} & =\rho_{g} g_{t-1}+\varepsilon_{t}^{g}, \\
g_{t}^{*} & =\rho_{g}^{*} g_{t-1}^{*}+\varepsilon_{t}^{g^{*}}, \\
\vartheta_{t} & =\rho_{\vartheta} \vartheta_{t-1}+\varepsilon_{t}^{\vartheta},
\end{aligned}
$$

while the non-stationary innovation to the union-wide technology shock, the monetary policy shock and price markup shocks are iid: $\varepsilon_{t}^{A}, \varepsilon_{t}^{m}, \varepsilon_{t}^{\mu^{C}}$, and $\varepsilon_{t}^{\mu^{C^{*}}}$. 